Research Article

\title{
Finite Element Analysis of Natural Thawing Heat Transfer of Artificial Frozen Soil in Shield-Driven Tunnelling
}

\author{
Yong Fu, ${ }^{1}$ Jun Hu ${ }^{D},{ }^{2}$ Jia Liu, $^{3}$ Shengbin Hu, ${ }^{4}$ Yunhui Yuan, ${ }^{5}$ and Hui Zeng ${ }^{6}$ \\ ${ }^{1}$ Department of Ocean Science and Engineering, Southern University of Science and Technology, Shenzhen 518055, China \\ ${ }^{2}$ College of Civil Engineering and Architecture, Hainan University, Haikou 570228, China \\ ${ }^{3}$ State Key Laboratory of Eco-Hydraulics in Northwest Arid Region, Xi'an University of Technology, Xi'an 710048, China \\ ${ }^{4}$ Nanning Rail Transit Co., Ltd., Nanning 530029, Guangxi Province, China \\ ${ }^{5}$ China Railway Liuyuan Group Co., Ltd., Tianjin 300133, China \\ ${ }^{6}$ College of Civil Engineering and Architecture, Wuyi University, Jiangmen 529020, Guangdong Province, China
}

Correspondence should be addressed to Jun Hu; hj7140477@hainanu.edu.cn

Received 28 November 2019; Revised 14 August 2020; Accepted 21 August 2020; Published 31 August 2020

Academic Editor: Hui Yao

Copyright (c) 2020 Yong Fu et al. This is an open access article distributed under the Creative Commons Attribution License, which permits unrestricted use, distribution, and reproduction in any medium, provided the original work is properly cited.

\begin{abstract}
The technology of artificial horizontal freezing method is increasingly being used in the soil reinforcement of urban underground projects such as shield-driven tunnelling. Compared with the freezing process, the thawing process is more complicated, and the thawing behavior of artificial frozen soil surrounding shield-driven tunnels has not been well investigated in both the academic and industrial domains. This study, therefore, aims to investigate the natural thawing heat transfer behavior of artificial horizontal frozen soil in shield-driven tunnelling using a three-dimensional finite element method. The finite element modelling is based on the horizontal freezing reinforcement project of Chating Station to Jiqingmen Station Tunnel in the Nanjing Metro Line 2. Validation between finite element results and site measured results is firstly conducted. The natural thawing temperature field contours as well as the radial and longitudinal distributions of natural thawing temperature in the frozen soil surrounding the tunnel are then explicitly examined. Furthermore, sensitivity analysis of influencing factors such as the thermal conductivity, latent heat of phase change, ambient temperature inside tunnel, freezing time, and original ground temperature is carried out. The results and findings of this study may enrich the current limited database and enable a better understanding of natural thawing heat transfer behavior of artificial frozen soil in shield-driven tunnelling.
\end{abstract}

\section{Introduction}

With the development of urban underground construction, artificial freezing method has been increasingly adopted in municipal engineering, especially in the construction of urban underground rail transit. For example, it has been used in the connection channels of subway tunnels, the reinforcement of shield tunnelling, and the repair projects of subway tunnel, obtaining a good reinforcement effect [1-5]. As a new technology to deal with various underground engineering problems, artificial freezing technology has good water-sealing performance and strong adaptability which enables pollution-free construction. However, with the increasing application of artificial freezing method in urban rail transit construction, the impact of its construction on the surrounding urban environment is becoming increasingly apparent. The ground subsidence caused by the thawing of artificial frozen soil is an important problem, which cannot be ignored in construction control. At present, most projects with artificial freezing construction adopted natural thawing methodology to thaw the artificial frozen soil after the completion of soil freezing. However, the natural thawing process usually takes a long period and it is difficult to track grouting, thus increasing the risk of ground subsidence and cracking. In order to improve the grouting efficiency and to control the melting and sinking capacity to the maximum extent, it is essential to grasp the spatial and 
temporal distribution law of thawing heat transfer behavior of artificial frozen soil.

In the past few years, researchers have explored the behavior of heat transfer of artificial frozen soil; however, most of the research studies are focused on the freezing process, $[3,6-8],[1,9,10]$, and [11-19]. In terms of the thawing process of artificial frozen soil especially for the investigation into the temperature field behavior of thawing process, there are very limited researches. A few researchers studied the microstructure and dynamic behavior of different types of soil during thawing using laboratory tests or geotechnical centrifuge model tests, [20-22] and [23-29]. Nevertheless, these studies were essentially concerned about the frozen soil itself without considering the surrounding buried structures. To solve this, Zhao et al. [30] explored the thawing temperature field of frozen soil surrounding an embedded oil pipeline. However, their research was aimed at the seasonal frozen soil in permafrost regions. He and Cui [31] examined the dynamic behavior of a thawing soil surrounding the tunnel which is subjected to vibrating loads. Li et al. [32] also reported the dynamic response of muddy clay surrounding the subway tunnel during freezing and thawing. For the study of thawing temperature field behavior of artificial frozen soil in shield-driven tunnelling, the existing database and relevant research are relatively limited, which hinders the development of thawing principle and thawing technology in the application of artificial freezing methodology.

Therefore, the objective of this study is to investigate the natural thawing heat transfer behavior of artificial horizontal frozen soil in shield-driven tunnelling using a three-dimensional finite element method. The finite element analysis is based on the real reinforcement project of Chating Station to Jiqingmen Station Tunnel in the Nanjing Metro Line 2 which adopted both artificial horizontal freezing technology and natural thawing methodology. In the analysis, the natural thawing temperature field contours as well as the radial and longitudinal distributions of natural thawing temperature in the frozen soil surrounding the shield-driven tunnel are explicitly examined. In addition, a series of sensitivity analyses on the typical influencing factors is performed. The results and findings of this study may enrich the current limited database and enable a better understanding of natural thawing temperature behavior of artificial frozen soil surrounding shield-driven tunnels.

\section{Natural Thawing of Artificial Frozen Soil and Mathematical Model for Temperature Field}

The natural thawing of natural permafrost is to melt the permafrost after the end of freezing via natural energy sources such as solar radiation energy, atmosphere, and surface water heat energy. The technology of natural thawing of artificial frozen soil is similar to that of natural permafrost which mainly relies on the heat convection between the frozen soil and the air and the heat transfer of the surrounding nonfrozen soil. The temperature of the frozen soil will slowly increase until reaching the phase change temperature; as a result, the ice in the frozen soil will melt and the natural thawing will be achieved. The technology of artificial freezing is usually applied in a small scale and in deeply embedded construction projects [1]. In urban areas, due to the restrictions of the surrounding environment, it is not convenient to conduct a manual intervention in the natural thawing process, so this process is often time-consuming.

The artificial horizontal freezing process will continue until the shield machine moves out of the tunnel portal. Hence, the natural thawing of frozen soil is mainly aimed at the outer annular frozen soil curtain. The natural thawing process is a heat transfer process and the mathematical model for the temperature field of the natural thawing of horizontal frozen soil curtain can, therefore, be derived. Following $\mathrm{Hu}$ et al. [13], in the frozen and unfrozen zones, that is, two sides of the outer boundary of frozen soil curtain, the governing differential equations of temperature field within a soil matrix can be expressed as

$$
C_{i} \frac{\partial T_{i}}{\partial t}=\lambda_{i}\left(\frac{\partial^{2} T_{i}}{\partial x^{2}}+\frac{\partial^{2} T_{i}}{\partial y^{2}}+\frac{\partial^{2} T_{i}}{\partial z^{2}}\right)
$$

where $C_{i}$ is the volumetric specific heat of soil in the frozen or unfrozen zones; $T_{i}$ is the temperature of the soil in the frozen or unfrozen zones; $t$ is the time; $\lambda_{i}$ is the thermal conductivity.

According to Rohsenow et al. [33], the temperature and heat flux on the boundaries are given as

$$
\begin{aligned}
\left.T\right|_{\Gamma} & =f(x, y, z, t), \\
-\left.k \frac{\partial T}{\partial n}\right|_{\Gamma} & =g(x, y, z, t) .
\end{aligned}
$$

At the interface between the tunnel segment and the air inside the tunnel, since the frozen soil is directly exposed to the ambient temperature inside the tunnel, there is natural convection between the air in the tunnel and the frozen soil. The heat flux at the interface can then be expressed as

$$
-\left.k \frac{\partial T}{\partial n}\right|_{\Gamma}=\left.\alpha\left(T-T_{f}\right)\right|_{\Gamma}
$$

where $\Gamma$ refers to the boundary; $f(x, y, z, t)$ is the temperature function; $g(x, y, z, t)$ is the heat flux function; $\alpha$ is the heat transfer coefficient; and $T_{f}$ is the temperature of fluid medium, that is, the air inside the tunnel.

The natural thawing process of frozen soil is a phase change heat conduction problem where the latent heat of phase change should be considered. The latent heat of phase change refers to the heat released or absorbed due to the change between the water solid and the liquid phase. The principle of enthalpy method [34] is adopted to solve the phase change process in ADINA, and the latent heat of phase change can be calculated by

$$
Q=L \rho_{d}\left(w-w_{u}\right)
$$

where $Q$ is the latent heat; $L$ is the latent heat of crystallization or fusion of water; that is, $L=334.56 \mathrm{~kJ} / \mathrm{kg}$; $\rho_{d}$ is dry 
density of soil; $w$ is the total water content; and $w_{u}$ is the unfrozen water content in the frozen soil.

At the phase transition interface,

$$
\begin{gathered}
T_{s}(x, t)=T_{l}(x, t)=T_{f}, \\
T_{s}(y, t)=T_{l}(y, t)=T_{f}, \\
T_{s}(z, t)=T_{l}(z, t)=T_{f}, \\
{\left[K_{s}\left(\frac{\partial T_{s}}{\partial x}\right)-K_{l}\left(\frac{\partial T_{l}}{\partial x}\right)\right]+\left[K_{s}\left(\frac{\partial T_{s}}{\partial y}\right)-K_{l}\left(\frac{\partial T_{l}}{\partial y}\right)\right]} \\
+\left[K_{s}\left(\frac{\partial T_{s}}{\partial z}\right)-K_{l}\left(\frac{\partial T_{l}}{\partial z}\right)\right]=L \rho \frac{\mathrm{d} X(t)}{\mathrm{d} t},
\end{gathered}
$$

where $X(t)$ is phase interface position; $K_{s}$ and $K_{l}$ are the thermal conductivity of the solid and liquid phase, respectively; $T_{s}$ and $T_{l}$ are the temperature of the solid and liquid phase, respectively.

Since the specific heat and thermal conductivity of soil as well as the location of the two-phase interface vary with temperature $[35,36]$, the energy conservation condition at the interface is nonlinear. To solve the nonlinear problem, the technology of numerical modelling is therefore adopted. In this study, three-dimensional finite element modelling using the commercial software ADINA is conducted to investigate the behavior of natural thawing temperature field of artificial frozen soil in shield-driven tunnelling. This software has also been utilized by many other researchers in the study of temperature field of artificial frozen soils which verifies its capability $[1,37,38]$.

\section{Finite Element Modelling}

3.1. Background. The Chating Station to Jiqingmen Station Tunnel in the Nanjing Metro Line 2 was constructed using Earth Pressure Balanced Shield (EPBS). The diameter of the shield tunnel is $6.34 \mathrm{~m}$; the ground elevation is $+7.57 \mathrm{~m}$; the elevation of the uplink tunnel is $-4.275 \mathrm{~m}$; and the buried depth of the shield tunnel is $11.845 \mathrm{~m}$. The geological conditions surrounding the tunnel are complex; the soil layers mainly include filled soil, silty clay, mucky silty clay, and silty sand (Figure 1(a)). The soil in front of the opening for shield tunnelling was reinforced using three-axis cement mixing piles which form a waterproof diaphragm wall (Figure 1(a)). However, slight liquefaction in the silty clay and silty sand layers was observed which bears the risk of water and sand gushing during shield tunnelling. To overcome this, the artificial horizontal ground freezing technology was therefore adopted.

The layout of horizontal freeze pipes in and out of the shield tunnel is shown in Figure 1. A total of 57 freeze pipes were arranged in parallel and there are four freeze hole circles in the cross-sectional view. The length of the freeze pipes varies due to the complex geological conditions. For the upper half of the outer circle, the length of freeze pipes is $3 \mathrm{~m}$, while for the lower region, the length of freeze pipes was designed to be $6 \mathrm{~m}$ because this region lies in the silty sand layer which is more likely to cause the danger of water and sand gushing. For the region inside the tunnel, the length of freeze pipes is $2 \mathrm{~m}$ which can generate frozen soil blocks with sufficient compressive strength. The temperature of brine during active freezing ranges between $-25^{\circ} \mathrm{C}$ and $-30^{\circ} \mathrm{C}$. The time required for the closure of frozen soil curtain is approximately 22 days, while the time for achieving the designed strength is around 30 days. The ultimate thickness of the outer frozen soil curtain reaches $1.6 \mathrm{~m}$ and its average temperature is about $-10^{\circ} \mathrm{C}$.

3.2. Model Setup. Figure 2 shows the schematics of the threedimensional finite element model. Due to symmetry, only half of the soil and tunnel was modelled. The dimensions of the soil domain are $18 \mathrm{~m} \times 12 \mathrm{~m} \times 30 \mathrm{~m}$. The embedment depth of tunnel is the same as the field situation. The distance between the tunnel axis and the bottom boundary of soil is $21.17 \mathrm{~m}$ which is more than five times the radius of outer freeze pipe circle; hence, it is sufficient in the computation of a freezing problem. The width of the soil domain was taken as two times the length of lower freeze pipes, that is, $12 \mathrm{~m}$. The thickness of the diaphragm wall is $1 \mathrm{~m}$. The freezing pipes are arranged according to the actual site situation; Figures 2(a) and 2(b) provide the cross-sectional and side views of the finite element model. The three-dimensional models for the processes of artificial horizontal freezing and natural thawing are shown in Figures 2(c) and 2(d), respectively. The 8-node hexahedral element type was adopted and finer meshes were applied in the reinforced region near the tunnel portal. According to the freezing plan, the freezing process and the natural thawing process take 50 days and 120 days, respectively. The time step was set to be $24 \mathrm{~h}$ and $48 \mathrm{~h}$ for these two processes, respectively.

The transient heat conduction model with phase transition was used for the computation of temperature field in the processes of freezing and thawing. The initial temperature load at the brine inlet was programmed as a time function in accordance with the brine cooling plan (i.e., Table 1) and applied directly to the surface of the freezing pipe. The temperature at the ground surface and the temperature at the interface between the diaphragm wall and the air are set to be $4.9^{\circ} \mathrm{C}$ which is the average temperature of Nanjing during construction. The boundary at the interface between the air inside the tunnel and the concrete tunnel segments is a heat dissipation boundary. During the period of natural thawing, the ambient temperature in the tunnel rose somewhat; the average site monitoring temperature is around $10^{\circ} \mathrm{C}$. The heat dissipation coefficient was set to be $50 \mathrm{~kJ} /\left(\mathrm{h} \mathrm{m}^{2} \mathrm{~K}\right)$. In the computation, the initial temperature field was taken as the measured original ground temperature of $\sim 35^{\circ} \mathrm{C}$; this value is slightly high due to the hydration heat of cement which was generated from the reinforcement construction work at the north end of the station using the methods of deep stirring pile and compaction grouting before freezing. The temperature value of each node calculated in the ultimate 


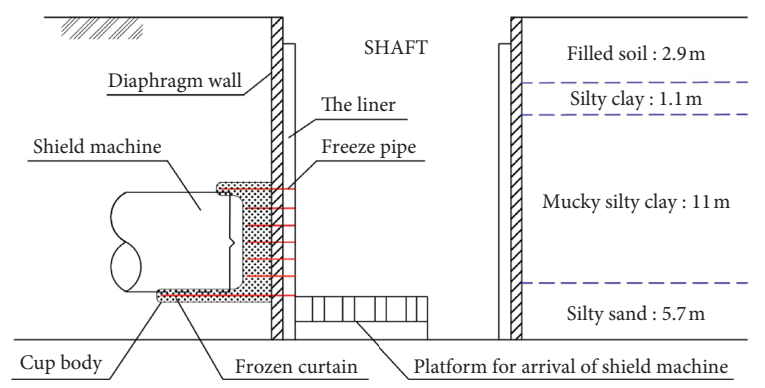

(a)

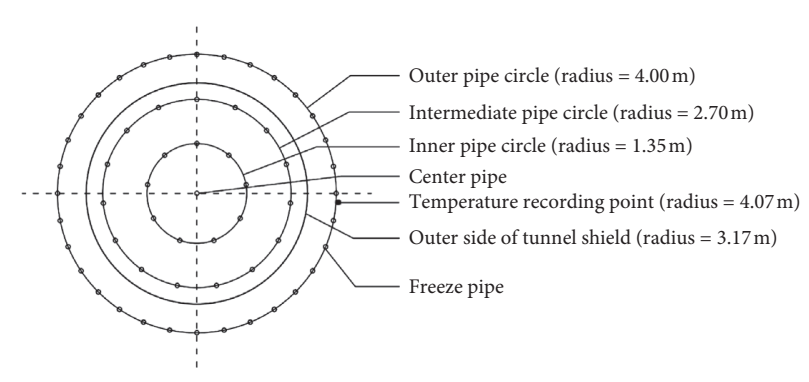

(b)

FIGURE 1: Layout diagram of horizontal freeze pipes in and out of shield tunnel: (a) longitudinal sectional view; (b) cross-sectional view.

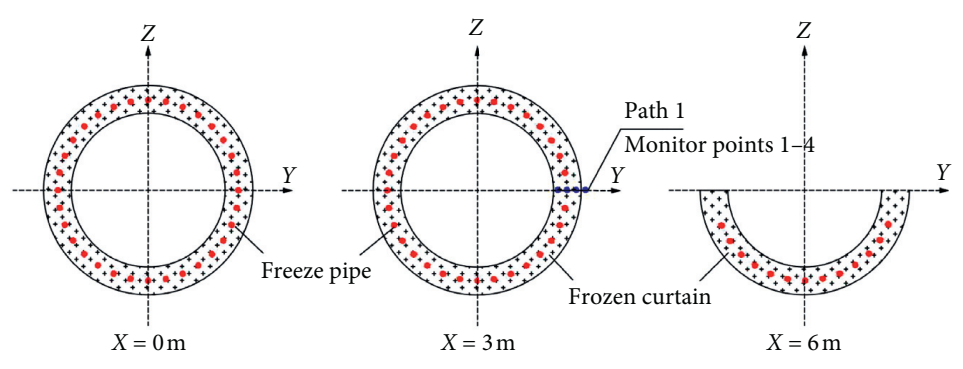

(a)

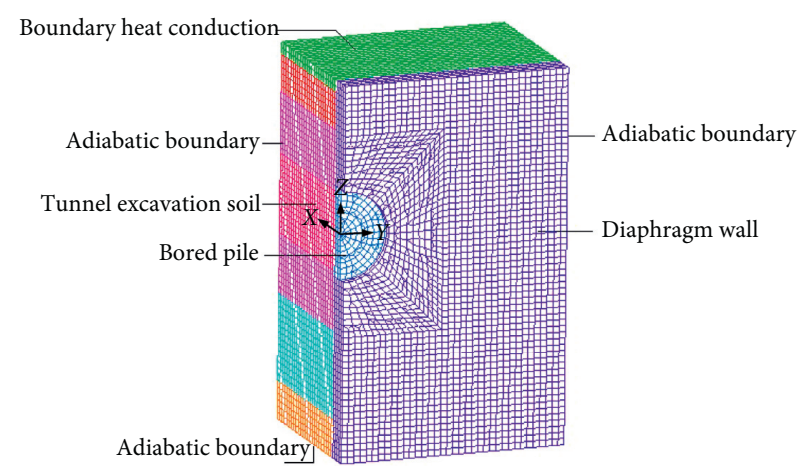

(c)

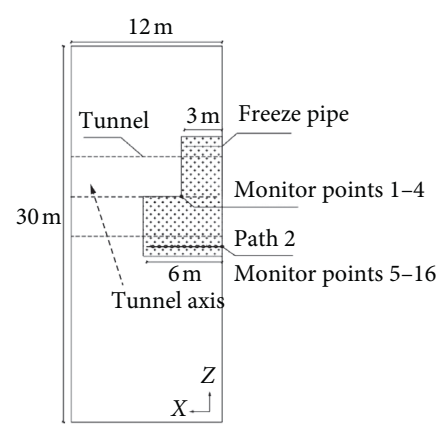

(b)

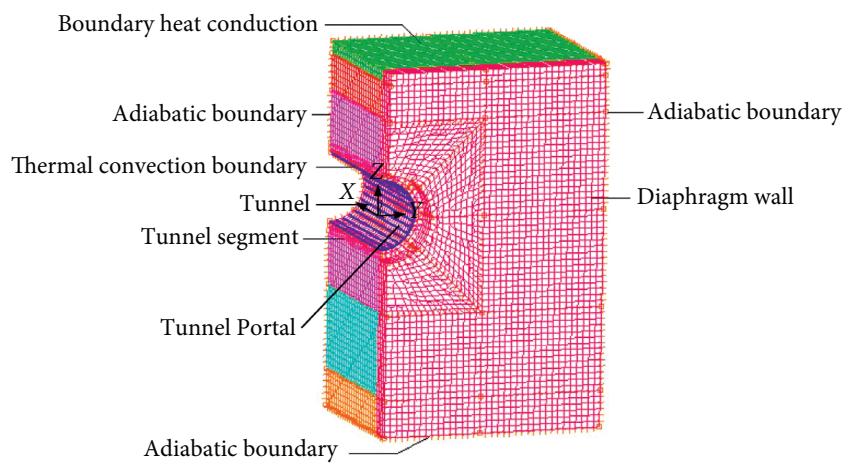

(d)

Figure 2: Schematics of finite element model: (a) cross-sectional views of shield tunnel; (b) section $y=0$; (c) 3D model for the horizontal freezing process; (d) 3D model for the natural thawing process. Notes: in Figure 2(a) from left to right, the monitor points are in the sequence of 1,2,3, and 4; in Figure 2(b) from right to left, the monitor points are in the sequence from 5 to 16.

TABLE 1: Brine cooling plan.

\begin{tabular}{lr}
\hline Freezing time $(\mathrm{h})$ & Inlet brine temperature $\left({ }^{\circ} \mathrm{C}\right)$ \\
\hline 0 & 20.0 \\
24 & 20.0 \\
168 & -24.0 \\
350 & -27.5 \\
720 & -27.5 \\
\hline
\end{tabular}


TABLe 2: Geotechnical parameters for different soil layers.

\begin{tabular}{|c|c|c|c|c|c|c|}
\hline Soil layers & Moisture content (\%) & Dry unit weight $\left(\mathrm{kN} / \mathrm{m}^{3}\right)$ & Liquid limit (\%) & Plastic limit (\%) & Plasticity index & Liquidity index \\
\hline Filled soil & 29.6 & 14.4 & 31.5 & 19.7 & 11.8 & 0.84 \\
\hline Silty clay & $25.7-37.6$ & $13.1-15.5$ & $31.6-47.2$ & $18.3-26.6$ & $12.3-20.6$ & $0.38-0.89$ \\
\hline Mucky silty clay & $32.2-49.1$ & $10.3-14.0$ & $31.4-49.4$ & $17.3-29.6$ & $11.8-19.8$ & $0.83-1.41$ \\
\hline Silty sand & $20.5-35.6$ & $13.3-16.8$ & - & - & - & - \\
\hline
\end{tabular}

TABLE 3: Thermal physical parameters for different soil layers.

\begin{tabular}{lccccc}
\hline \multirow{2}{*}{ Soil layers } & \multicolumn{2}{c}{ Thermal conductivity $\left(\mathrm{W} /\left(\mathrm{m} \cdot{ }^{\circ} \mathrm{C}\right)\right)$} & \multicolumn{2}{c}{ Specific heat capacity $\left(\mathrm{J} /\left(\mathrm{kg} \cdot{ }^{\circ} \mathrm{C}\right)\right)$} & Latent heat $\left(\times 10^{8} \mathrm{~J} / \mathrm{m}^{3}\right)$ \\
& Unfrozen soil & Frozen soil & Unfrozen soil & Frozen soil & 1250 \\
Filled soil & 1.34 & 2.12 & 1506 & 1330 & 0.97 \\
Silty clay & 1.35 & 2.22 & 1547 & 1321 & 0.78 \\
Mucky silty clay & 1.06 & 2.10 & 1717 & 1083 & 1.27 \\
Silty sand & 1.87 & 2.50 & 1473 & 1.23 \\
\hline
\end{tabular}

time step in the horizontal freezing model is extracted via the software postprocessing module which is subsequently imported into the natural thawing model as the initial temperature field. The bottom boundary and side boundaries were set to be adiabatic without heat transfer. Note that the heat transfer between the frozen soil and the shield is not considered in this study for simplicity.

The basic geotechnical physical parameters for different soil layers are given by the engineering geological investigation (Table 2). The thermal physical parameters are based on the laboratory results of typical soil layers in Nanjing District (Table 3).

3.3. Validation. The initial temperature field before thawing process was first computed. Figure 3 shows the three-dimensional contour of temperature field after 50 days' freezing time. As can be seen, the horizontal frozen soil curtain with a length of $\sim 3 \mathrm{~m}$ in the upper half part and a length of $\sim 6 \mathrm{~m}$ in the lower half part was well generated surrounding the tunnel in the regions near the diaphragm wall. The minimum and maximum temperature are $35^{\circ} \mathrm{C}$ and $-27.5^{\circ} \mathrm{C}$, which correspond to the ground temperature and the temperature at the brine inlet, respectively. This verifies the rationality of the established model and applied initial conditions.

The computed finite element results are validated with the measured natural thawing results at the temperature recording point (Figure 4 ). The temperature recording point lies $0.5 \mathrm{~m}$ below the axial plane and $3 \mathrm{~m}$ off the diaphragm wall $(X=3 \mathrm{~m})$ (Figure $1(\mathrm{~b}))$. Due to the requirement for engineering progress, the natural thawing temperature was only recorded for 30 days. On the other hand, the monitor point 2 on Path 1 in the $Y Z$-plane at $X=3 \mathrm{~m}$ which locates on the freezing pipe was taken for comparison (Figure 2(a)). As shown in Figure 4, the computed results agree reasonably well with the measured results although some hysteresis occurs. This hysteresis is probably due to the following reasons. Firstly, the hydrodynamic effect on the heat exchange process which existed in the real situation was mot modelled in the finite element analysis. For example, a phenomenon such as a seepage on the ground may occur which may in turn affect the temperature distribution during freezing. Secondly, the numerical simulation assumed the real inhomogeneous and discontinuous soil to be homogeneous isotropic. Thirdly, the thermal physical parameters in the computations were taken from those of the typical soil layers in Nanjing District; however, for the specific region of the tunnel near Jiqingmen Station, the real values may be somewhat different. Fourthly, compared with the monitor point 2 in the computations, the position of the temperature recording point is slightly farther away from the thermal convection boundary of the tunnel segments. As a result, the measured temperatures in the same time should be slightly lower than the computed values.

\section{Results and Analysis}

4.1. Temperature Field Contour Plot. The temperature field contour plot of the cross section in the YZ-plane at $X=3 \mathrm{~m}$ at different natural thawing time (i.e., 0 days to 120 days) is shown in Figure 5. This cross section locates at the end of the upper $3 \mathrm{~m}$ long frozen pipes above the tunnel axis plane and at the middle of the lower $6 \mathrm{~m}$ long frozen pipes below the tunnel axis plane. As can be seen, the frozen zone lies in the surrounding of tunnel and the minimum temperature occurs at the outer freeze pipe circle. In the region outside the outer freeze pipe circle, the temperature increases with the radial distance away from the outer pipe circle. As the natural thawing time accumulates from 0 days to 120 days, the temperature of soil surrounding the tunnel rises progressively, whereas the temperature of soil far away from tunnel reduces gradually. Due to the difference in the length of freeze pipes above and below the tunnel horizontal axis plane, the frozen soil curtain above the axis plane thaws faster than that below the axis plane. For instance, the frozen curtain above and below the axis plane fully thaws after times of about 40 days and 60 days, respectively.

Figure 6 also shows the $0^{\circ} \mathrm{C}$-thawing isotherm plot in the $X Z$-plane at $Y=0$ with different thawing times. As can be seen, the zone enveloped by $0^{\circ} \mathrm{C}$-thawing isotherm shrinks as the thawing time increases and the rate of shrinkage varies a 


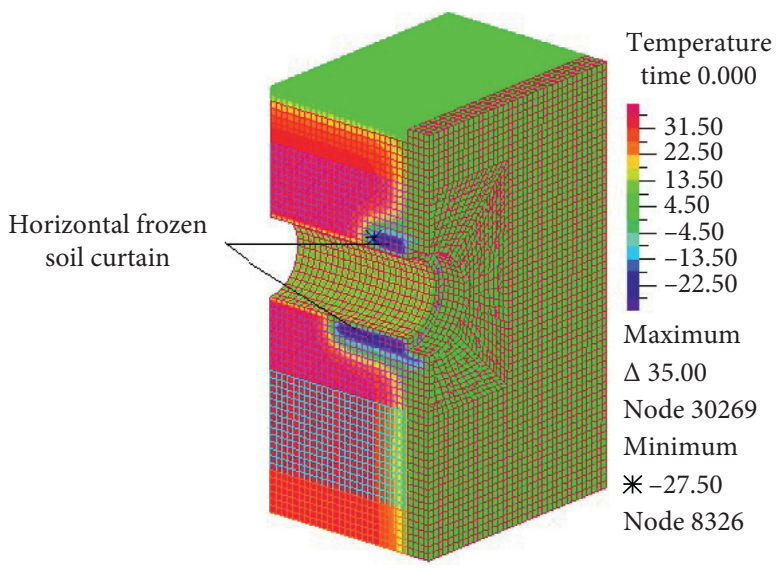

Figure 3: Frozen soil curtain after 50 days' freezing time.

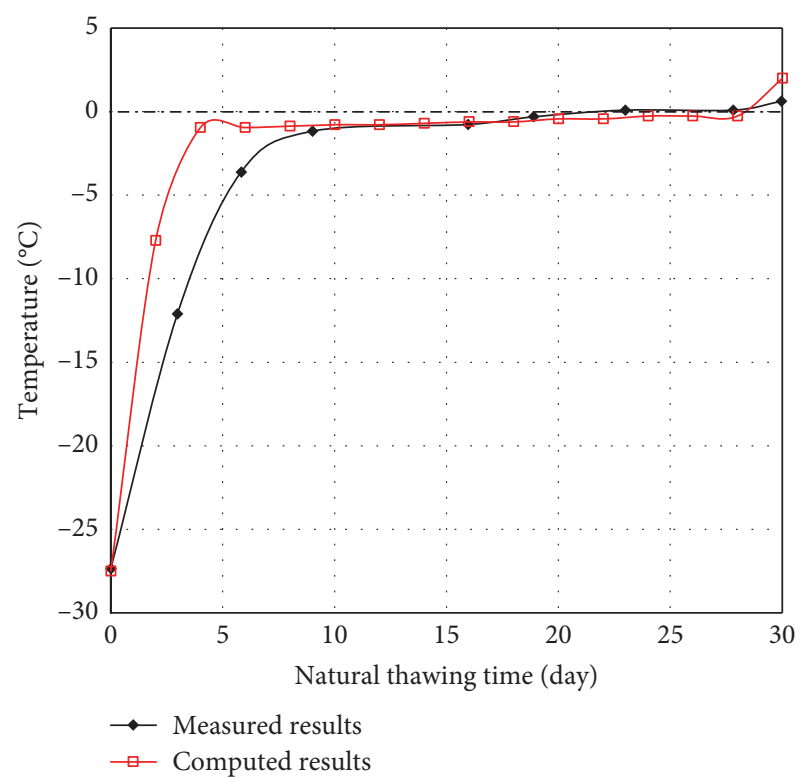

FIgURE 4: Comparison of measured and computed results of temperature-thawing time response.

lot in different regions. For example, the shrinkage rate at the side closer to the tunnel is very consistent, while at the other side farther from the tunnel, the rate is more affected by the surrounding ground temperature field, thus exhibiting inconsistent behavior. This behavior is more obvious in the regions near the end of freezing pipes which manifests a markedly faster rate than its counterparts in other regions. Moreover, the shrinkage behavior mainly occurs in the first 50 days of natural thawing; after 50 days' time, the change in the $0^{\circ} \mathrm{C}$-thawing isotherm is relatively minor indicating that the thawing rate has slowed down in this period and the natural thawing has almost finished.

4.2. Radial and Longitudinal Distributions of Temperature. Two paths with 16 monitor points were selected for examination of the radial and longitudinal variations of temperature with natural thawing time (Figures 2(a) and 2(b)). Path 1 with monitor points 1 to 4 lies along the radial direction in the $Y Z$-plane at $X=3 \mathrm{~m}$ (Figure 2(a)), while Path 2 with monitor points 5 to 16 locates in the longitudinal direction along the bottom freezing pipe in the $X Z$-plane (Figure 2(b)). The spacing distance between adjacent monitor points is $0.5 \mathrm{~m}$.

Figure 7 shows the variation of temperature with natural thawing time at monitor points 1 to 4 along Path 1 . As can be seen, the variation of temperature with thawing time mainly consists of three stages. In stage 1 , the temperature increases sharply with thawing time within two to seven days which is probably attributed to the effects of boundary convection and ground temperature. In terms of the ascending rate, monitor point 2 which sits on the freeze pipe gives the highest rate of $3.8^{\circ} \mathrm{C} /$ day, whereas the rates of monitor points 1 and 3 which, respectively, have $0.5 \mathrm{~m}$ offset inwardly and outwardly from freeze pipe are very close, although the inward monitor point 1 shows a slightly higher rate value, that is, $2.6^{\circ} \mathrm{C} /$ day versus $1.7^{\circ} \mathrm{C} /$ day. This may be because the frozen soil around monitor 1 directly contacts the tunnel segments; as a result, it is more influenced by the air convection in the tunnel. As for the monitor point 4 which lies the furthest away from the freeze pipe, it unexpectedly shows the lowest ascending rate of $0.3^{\circ} \mathrm{C} /$ day. The behavior of the initial ascending rate in the radial direction is also reflected in Figure 8(a) which plots the radial variation of temperature time at monitor points 1 to 4 along the radial direction, that is, Path 1. Stage 2 is the phase change stage in which the temperature becomes more stable and remains almost unchanged. In this stage, the maximum phase change time occurs at the position of freeze pipe, that is, monitor 2 , which is approximately 22 days, while at the other positions, the phase change time remains relatively short; that is, the phase change time at monitor 1 is around 2 days. At the position with $1 \mathrm{~m}$ offset outwardly from freeze pipe, that is, monitor 4 , although there is no phase change process, the temperature ascending rate slows down significantly within the time range of 10 days and 40 days due to the heat absorption during the nearby ice-water phase change process in the frozen zone. Following the phase change stage, the variation 


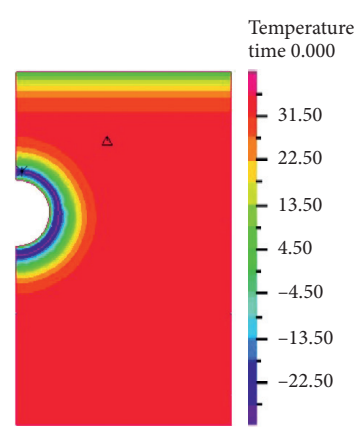

(a)

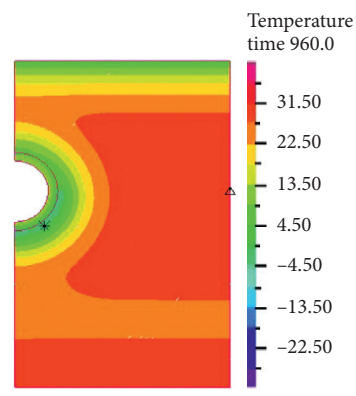

(e)

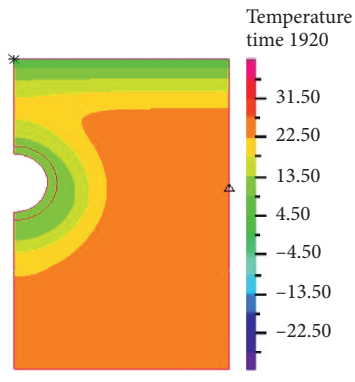

(i)

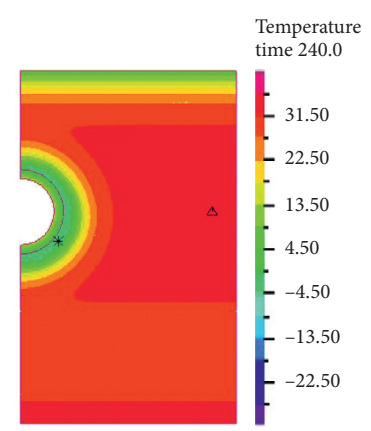

(b)

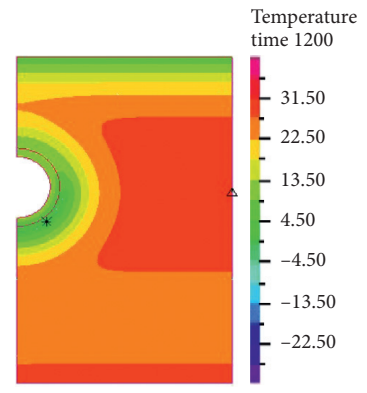

(f)

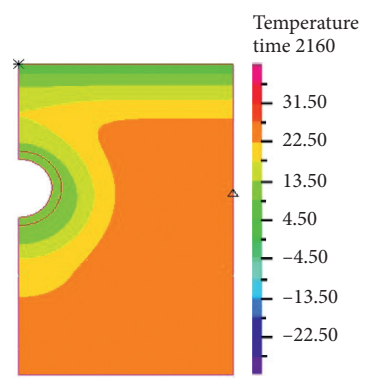

(j)

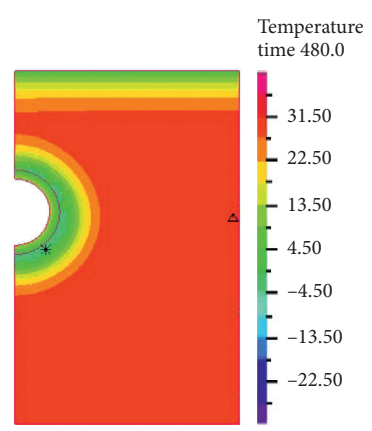

(c)

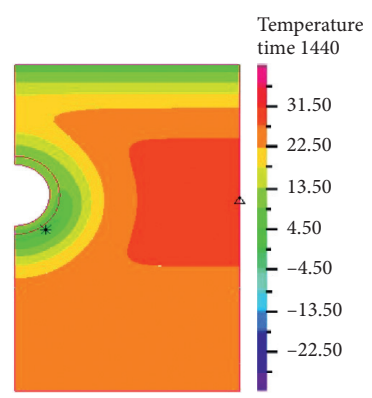

(g)

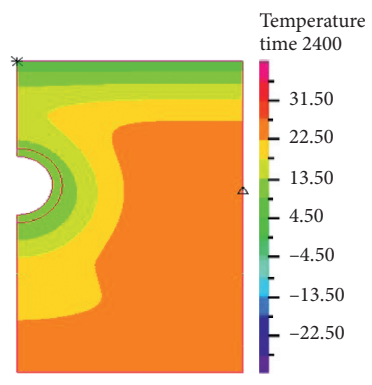

(k)

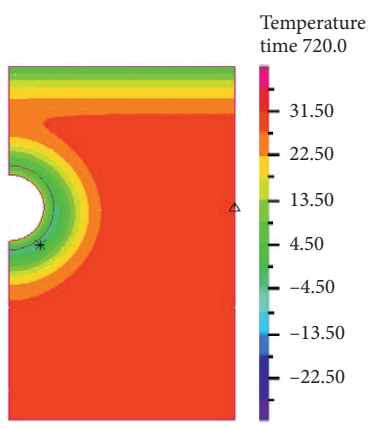

(d)

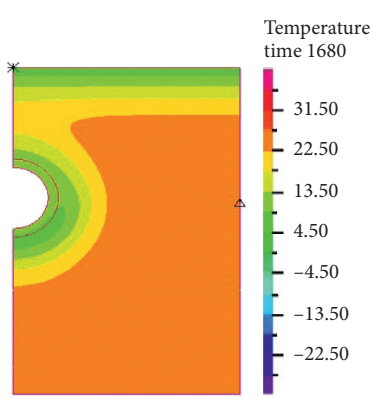

(h)

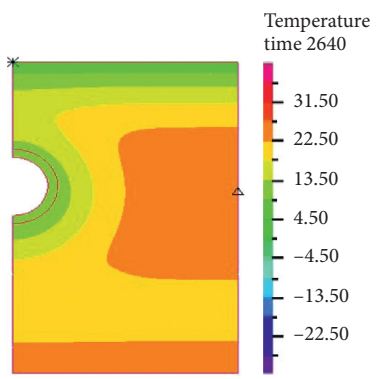

(1)

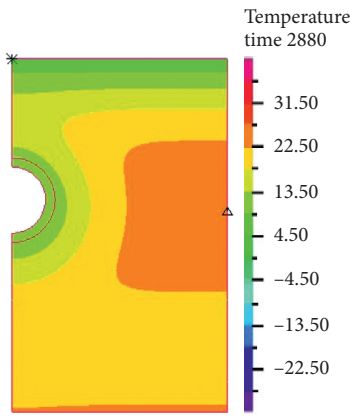

(m)

Figure 5: Temperature field contour plots at section of $X=3 \mathrm{~m}$ with different natural thawing times: (a) 0 days; (b) 10 days; (c) 20 days; (d) 30 days; (e) 40 days; (f) 50 days; (g) 60 days; (h) 70 days; (i) 80 days; (j) 90 days; (k) 100 days; (l) 110 days; (m) 120 days. 


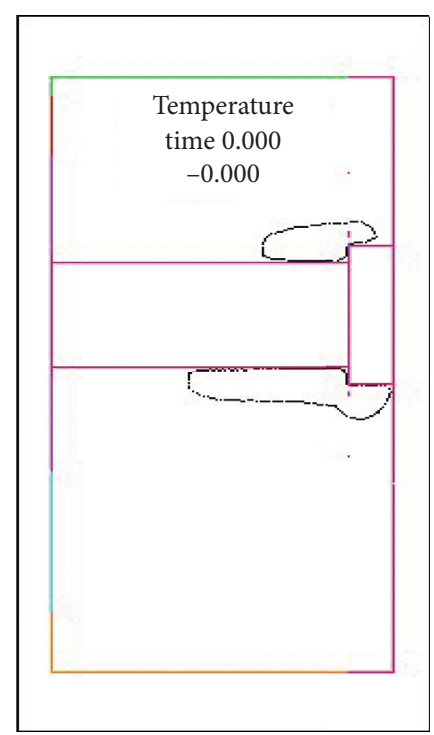

(a)

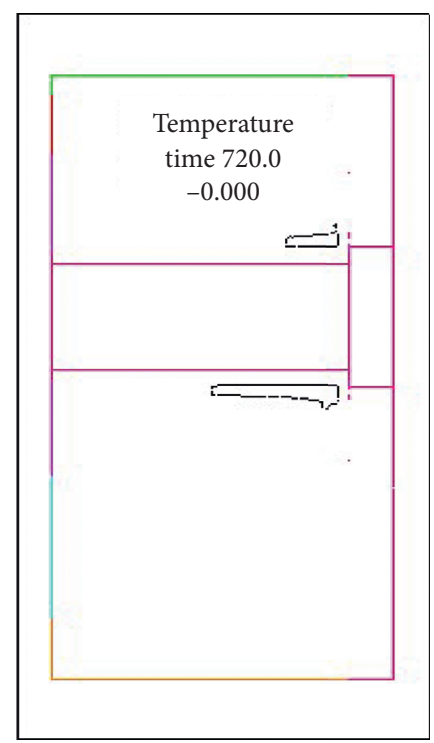

(d)

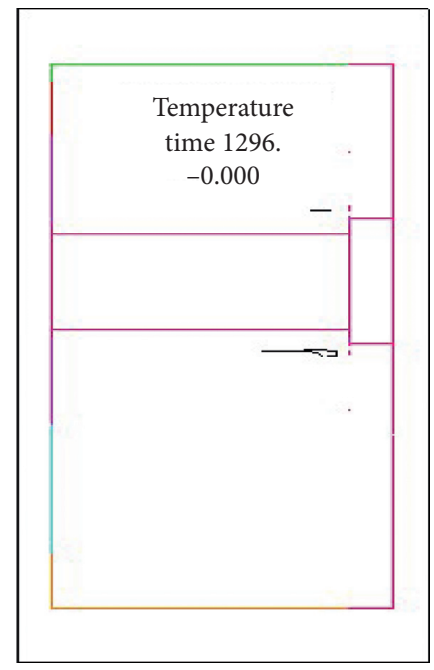

(g)

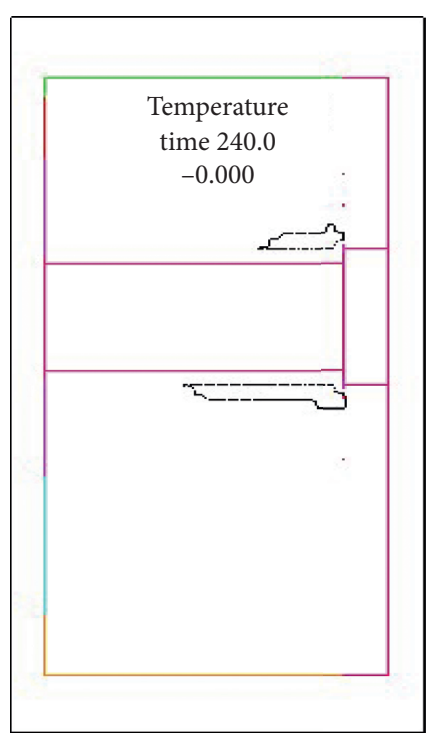

(b)

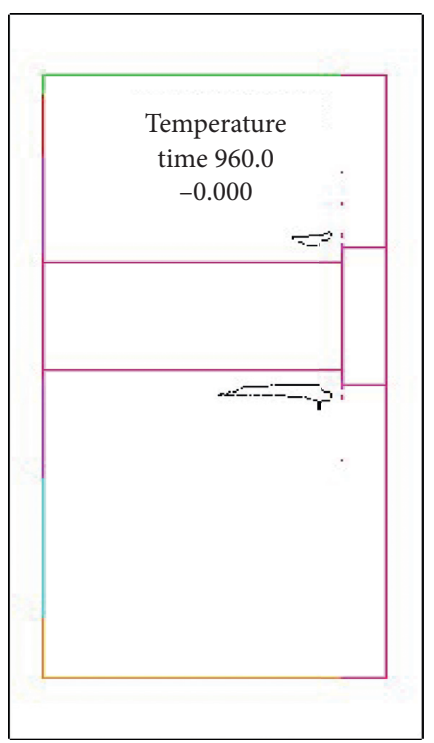

(e)

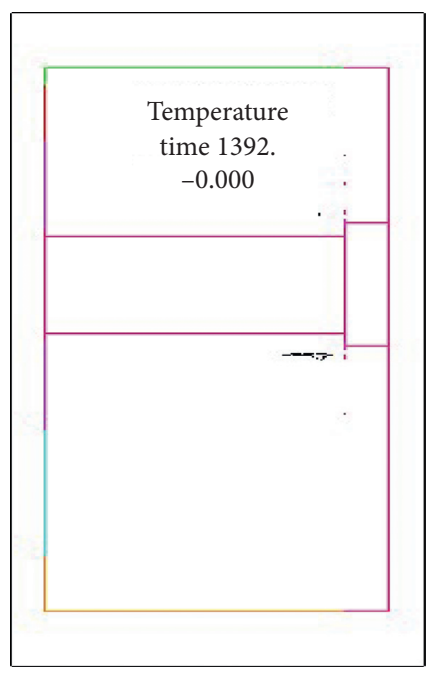

(h)

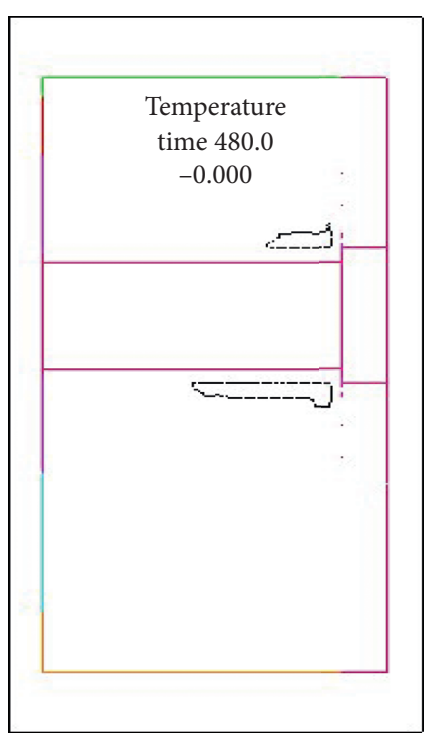

(c)

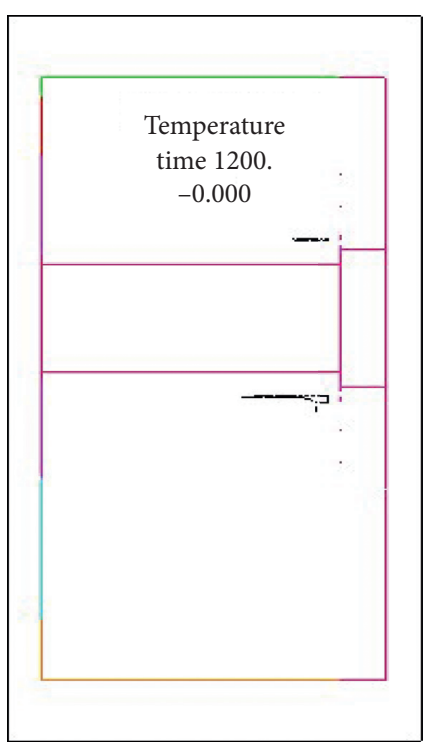

(f)

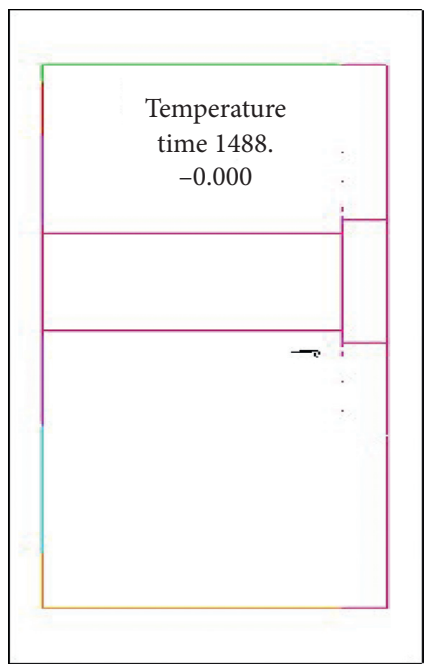

(i)

Figure 6: $0^{\circ}$ isotherm plots at section of $Y=0$ with different natural thawing times of (a) 0 days, (b) 10 days, (c) 20 days, (d) 30 days, (e) 40 days, (f) 50 days, (g) 54 days, (h) 58 days, and (i) 62 days. 


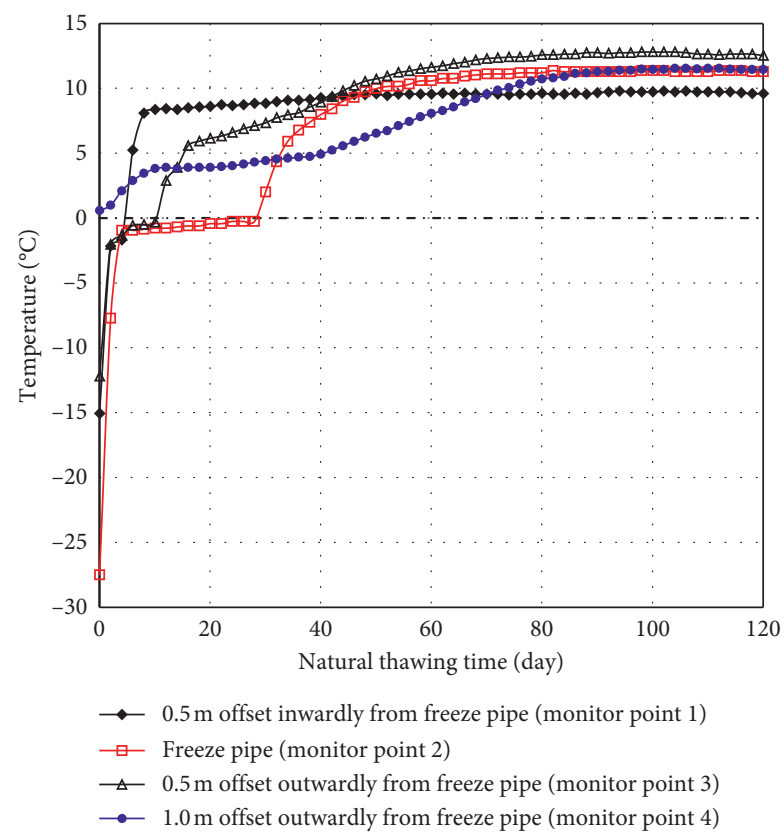

FIGURE 7: Variation of temperature with natural thawing time at monitor points 1 to 4 along Path 1.

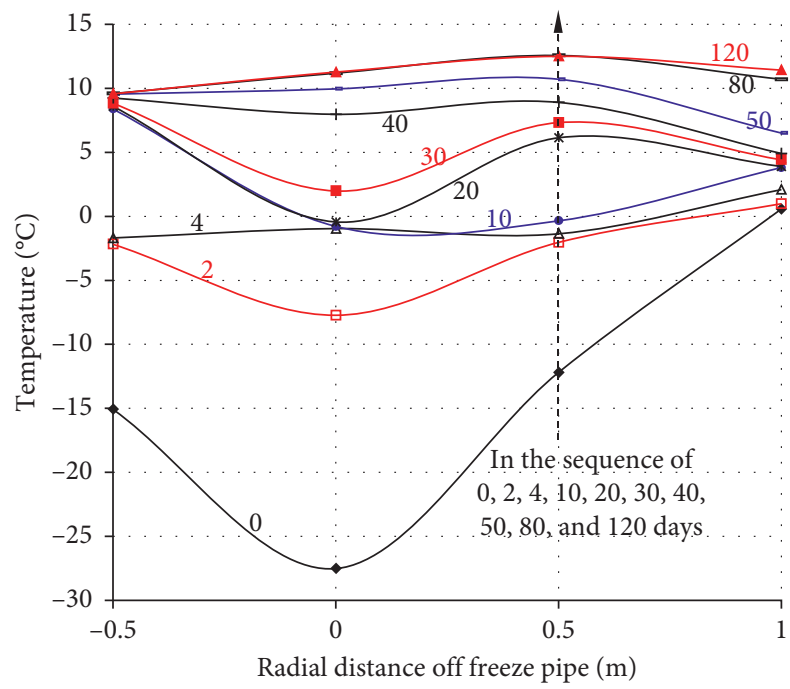

(a)

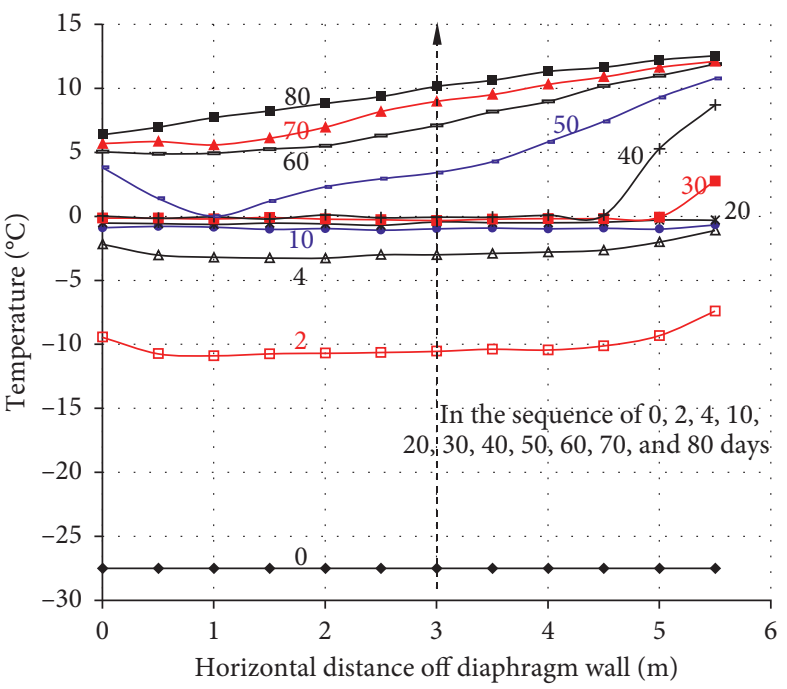

(b)

Figure 8: Variation of temperature with natural thawing time along the radial and longitudinal directions: (a) radial direction (Path 1); (b) longitudinal direction (Path 2).

of temperature enters stage 3 in which the temperature increases rapidly until reaching the maximum value. In this stage, the temperature at the inward monitor point 1 peaks first followed by monitor points 2,3 , and 4 . This three-stage behavior is similar to that reported by Zhou and Tang $[22,29]$ which investigated the thawing behavior of mucky clay using centrifuge model tests. According to the curve of the variation of the minimum temperature in the horizontal frozen soil curtain with natural thawing time (i.e., Figure 9), the required thawing time for the whole frozen soil curtain is approximately 72 days. The minimum temperature during thawing is located near the position of freeze pipes. Moreover, in this figure, the three-stage behavior for the whole frozen curtain can also be well observed.

The spatial distribution of the natural thawing temperature of frozen soil curtain is shown in Figure 8. This includes the radial and longitudinal distributions of thawing temperature along Path 1 and Path 2, respectively. As shown 


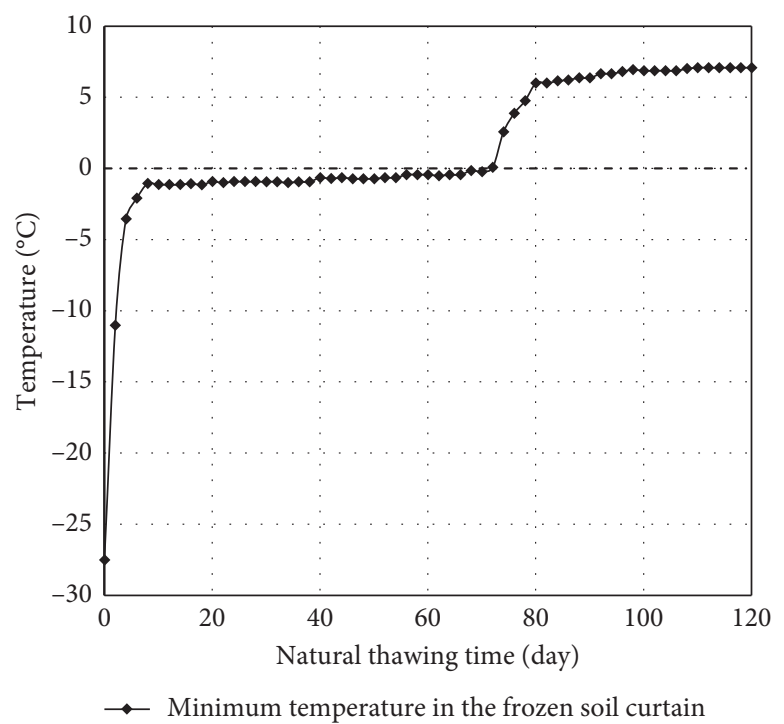

FIGURE 9: Variation of minimum temperature in the frozen soil curtain with natural thawing time.

in Figure 8(a), the initial lowest temperature occurs at the position of freeze pipe which is $-27.5^{\circ} \mathrm{C}$, while the initial temperature at the two sides of the freeze pipe rises approximately linearly with the offset radial distance. As mentioned above, the temperature rise rate at the position of freeze pipe is faster than its counterparts at the other positions; in return, the temperature at different positions along the radial direction, that is, Path 1 , tends to converge when the temperature starts to turn positive. After that, the temperature at the other positions continues to increase gently except for that on the freeze pipe which has to go through a long period of phase change. After a natural thawing time of about 40 days, the temperature at different radial positions becomes more and more stable which ultimately reaches a constant value of around $10^{\circ} \mathrm{C}$ which is equal to the ambient temperature inside the tunnel. The specific values of temperature gradient inwardly and outwardly from freeze pipe with different thawing times are provided in Table 4. In accordance with the linear interpolation principle, the position of the phase interface and its advance speed can be evaluated. As can be seen in Figures 10 and 11 , at the beginning when the natural thawing time is less than $\sim 5$ days, the phase interface approaches the freeze pipe rapidly with a speed of around $16 \mathrm{~cm} /$ day. When the thawing time exceeds $\sim 5$ days, its advance speed starts to drop dramatically which finally stabilizes when the thawing time is more than $\sim 12$ days.

Figure 8 (b) shows the longitudinal variation of temperature along Path 2 which is in the direction of $X$-axis. As can be seen, before the completion of thawing, the temperature in the $X$-axis direction along Path 2, that is, the direction of tunnelling, is relatively uniform and it is basically unaffected by the thermal conductivity in this direction. After entering the positive temperature zone, it gradually presents the behavior that the farther away from the diaphragm wall, the higher the temperature. This is mainly due to the high temperature of the soil below Path 2 and the lower ambient temperature inside the tunnel. From the perspective of required thawing time at different positions along Path 2 (i.e., Figure 12), at the position with $2 \mathrm{~m}$ offset from diaphragm wall, the required thawing time is the longest which is 50 days, while when deviating from this position, the required thawing time decreases successively. The shortest time required for thawing occurs at the furthest position away from the diaphragm wall which is around 20 days; thus, the influence of ground temperature on the natural thawing of the horizontal frozen soil curtain in the tunnelling direction cannot be ignored.

\section{Sensitivity Analysis of Influencing Factors}

Based on the aforementioned mathematical model of temperature field of natural thawing of horizontal frozen soil curtain as well as the above finite element results, the influencing factors of the temperature field of natural thawing of horizontal frozen soil curtain mainly involve thermal conductivity, volumetric heat capacity, latent heat of phase change, ambient temperature inside tunnel, freezing time, and original ground temperature. In the following, sensitivity analysis of these factors will be carried out.

5.1. Effect of Thermal Conductivity. Thermal conductivity refers to the amount of heat flowing through a material per unit temperature gradient per unit time which is a typical thermal physical parameter to characterize the thermal conductivity performance of a material. It is related to the composition, density, moisture content, and temperature of the material [39]. To examine the effect of thermal conductivity on the natural thawing temperature field, the thermal conductivity of the soil layer where the tunnel is located, that is, mucky silty clay layer, was reduced and increased by $20 \%$ and $40 \%$, respectively, in the finite element modelling. Since the initial conditions of the natural thawing 
TABLE 4: Temperature gradient inwardly and outwardly from freeze pipe with different thawing times.

\begin{tabular}{lcc}
\hline Thawing time (day) & Temperature gradient outwardly $\left({ }^{\circ} \mathrm{C} / \mathrm{m}\right)$ & Temperature gradient inwardly $\left({ }^{\circ} \mathrm{C} / \mathrm{m}\right)$ \\
\hline 0 & 28.0 & 14.9 \\
2 & 8.8 & 7.0 \\
4 & 3.1 & 0.6 \\
10 & 4.6 & 9.7 \\
20 & 4.3 & 9.6 \\
30 & 2.5 & 7.4 \\
40 & -3.1 & 1.7 \\
50 & -3.4 & 0.1 \\
80 & -0.6 & -1.1 \\
120 & -0.1 & -1.2 \\
\hline
\end{tabular}

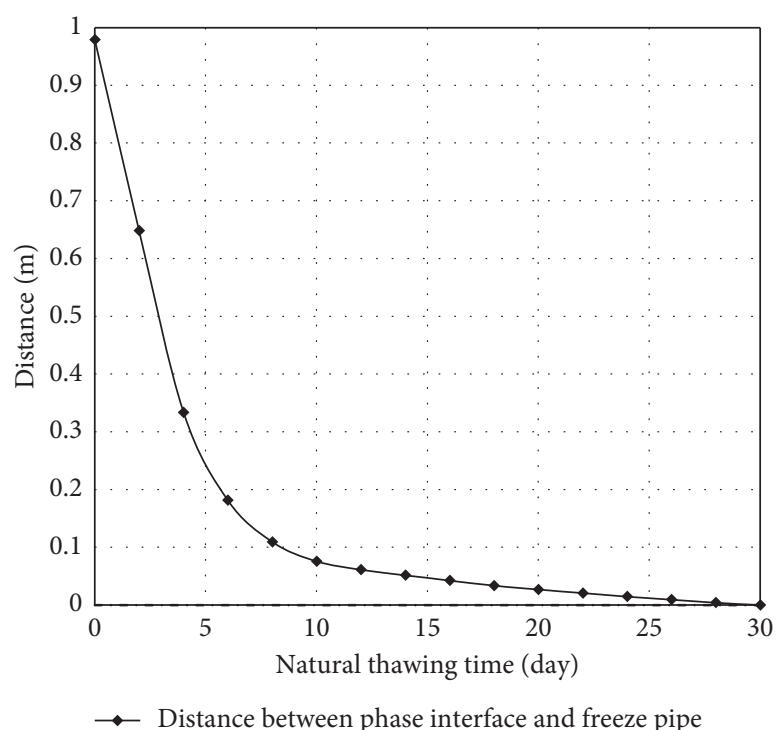

FIGURE 10: Variation of distance between phase interface and freeze pipe with natural thawing time.

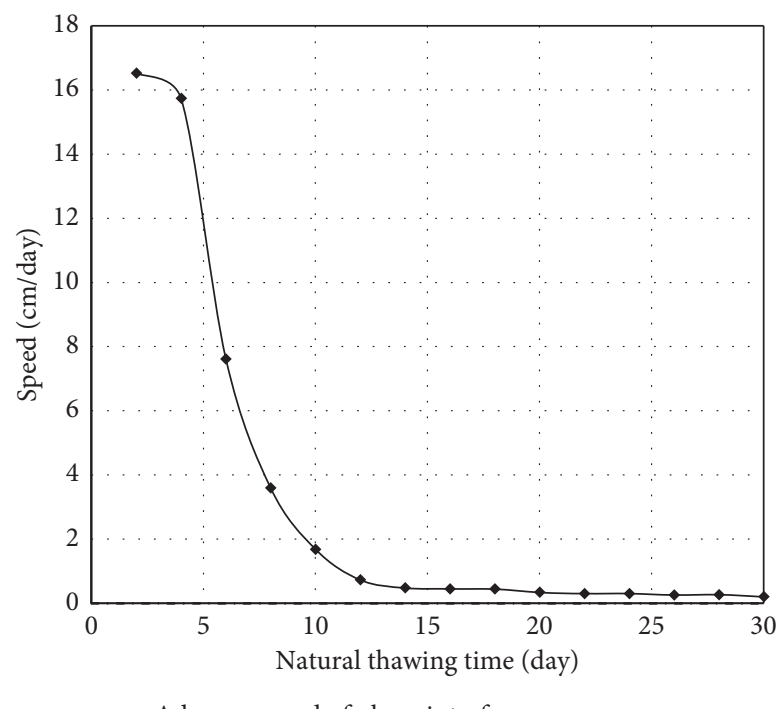

- Advance speed of phase interface

FIGURE 11: Variation of advance speed of phase interface with natural thawing time. 


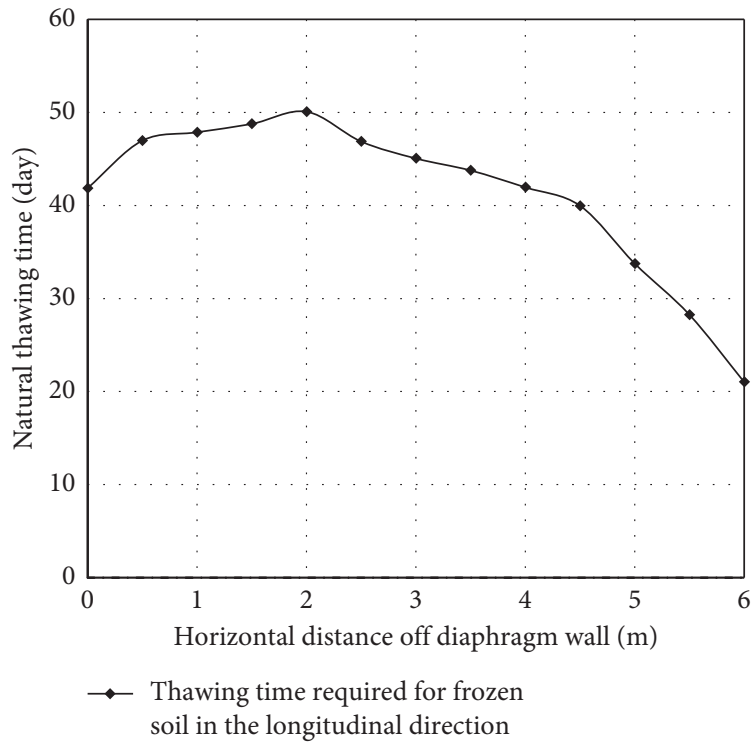

Figure 12: Thawing time required for frozen soil in the longitudinal direction along Path 2.

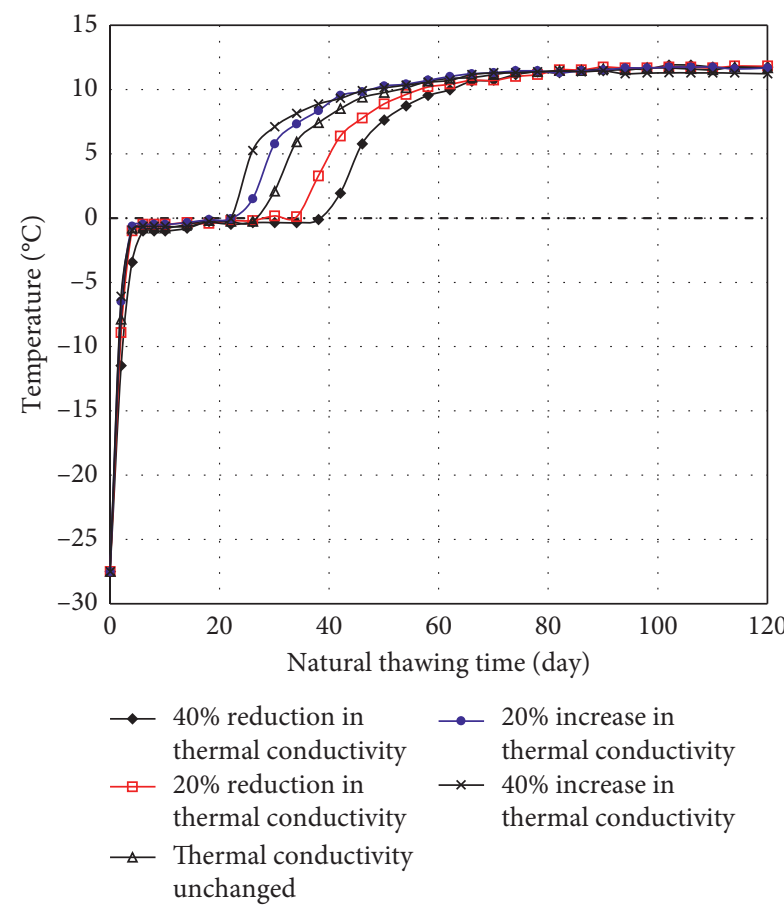

(a)

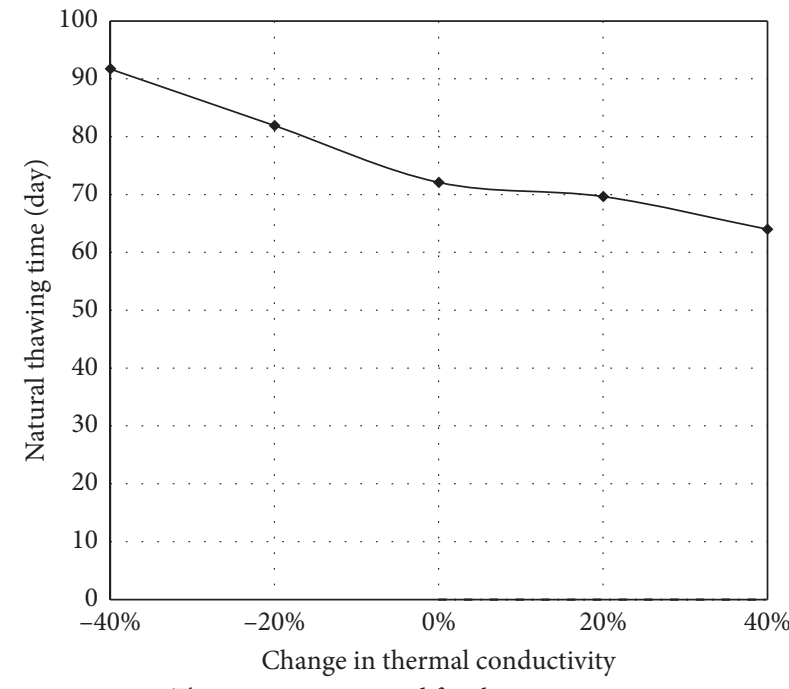

$\rightarrow-$ Thawing time required for the whole frozen soil curtain

(b)

FIGURE 13: Effects of thermal conductivity on the temperature-thawing time response and required thawing time for frozen soil curtain: (a) temperature-thawing time response at $X=3 \mathrm{~m}$ (monitor point 2); (b) variation of required thawing time with thermal conductivity change.

temperature field are based on the final temperature field of the freezing process, the freezing process was recomputed after changing the thermal conductivity.

Figure 13 shows the results of temperature-thawing time response and required thawing time for frozen soil curtain for cases with different thermal conductivity. Monitor point 2 with $X=3 \mathrm{~m}$ (i.e., Figure 2) was taken for analysis. As shown in Figure 13(a), the effect of the change in thermal conductivity on the natural thawing process is mainly reflected in the phase change time. Specifically, the phase 


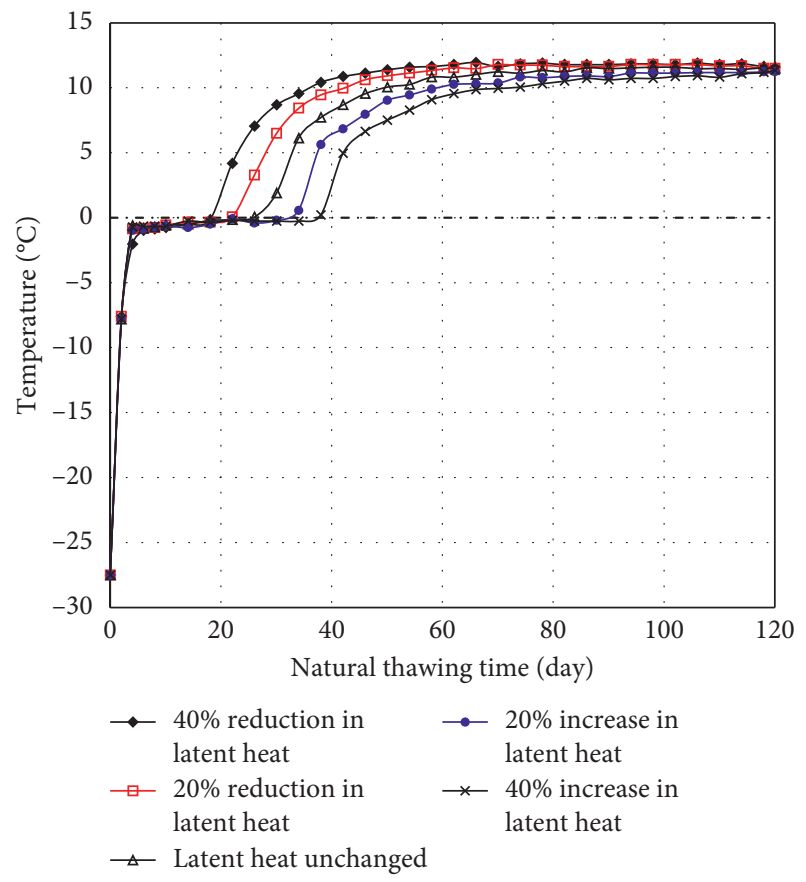

(a)

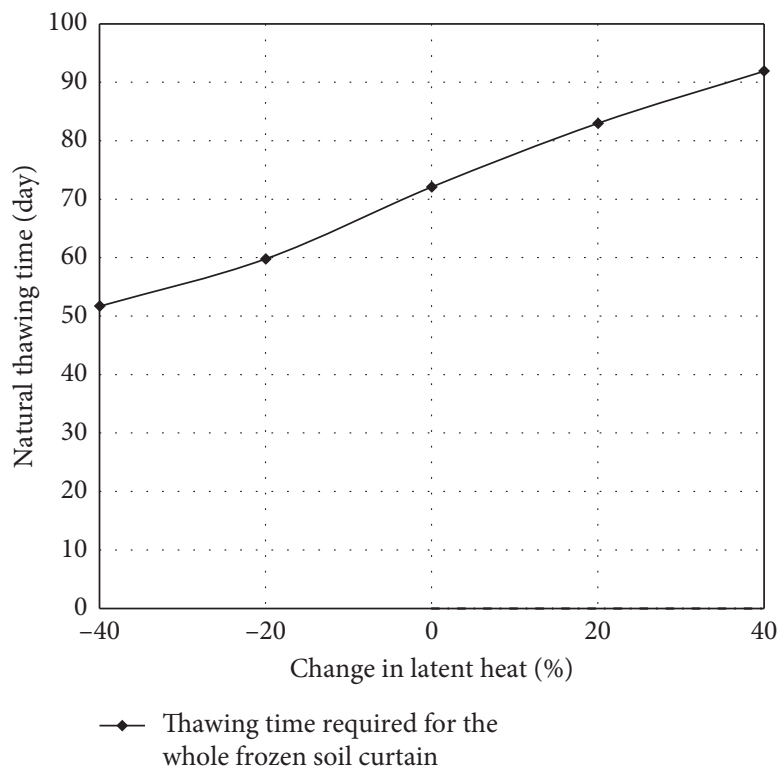

(b)

FIGURE 14: Effects of latent heat on the temperature-thawing time response and required thawing time for frozen soil curtain: (a) temperature-thawing time response at $X=3 \mathrm{~m}$ (monitor point 2); (b) variation of required thawing time with latent heat change.

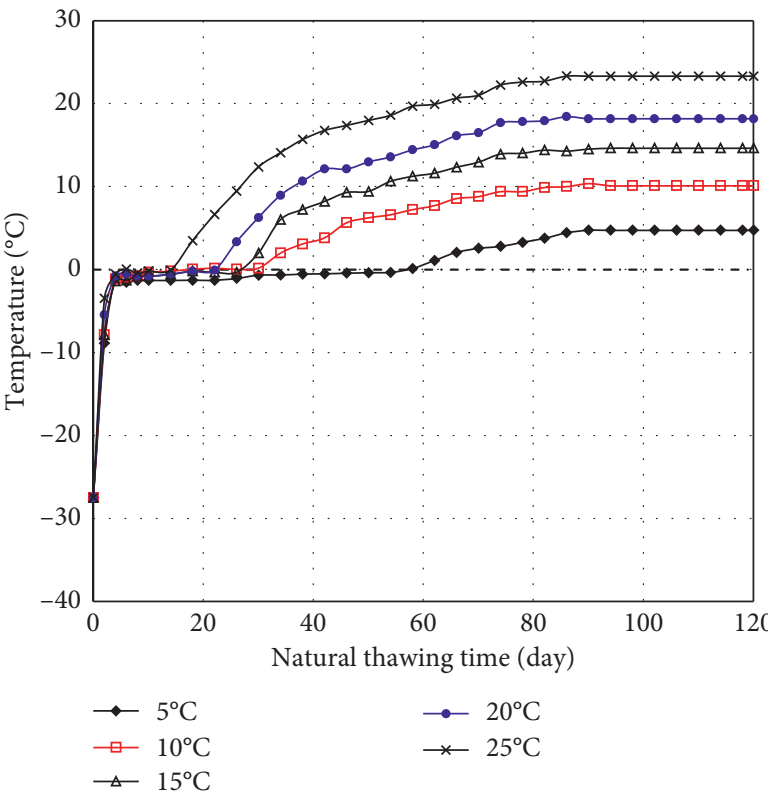

(a)

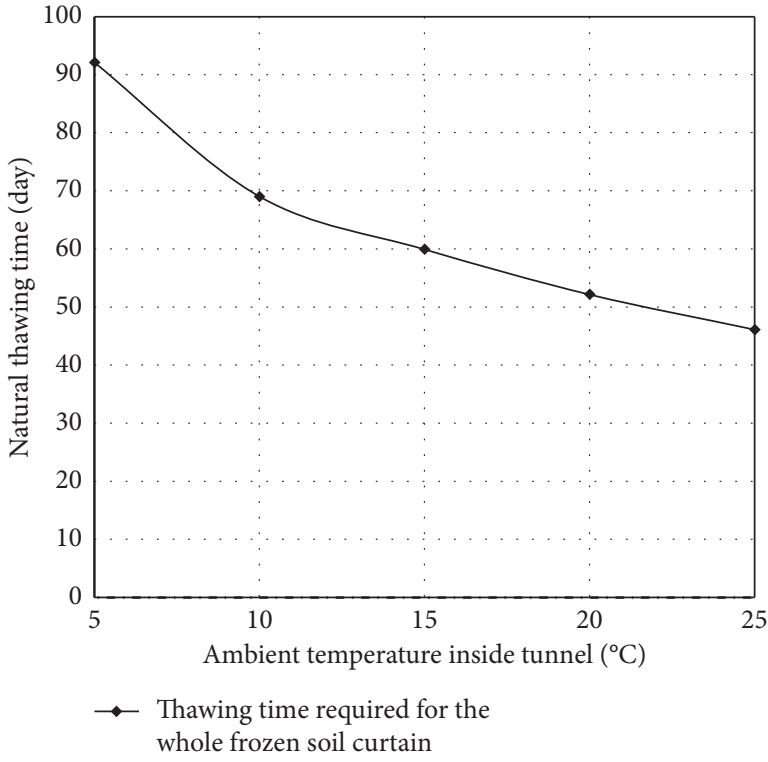

(b)

FIGURE 15: Effects of ambient temperature inside tunnel on the temperature-thawing time response and required thawing time for frozen soil curtain: (a) temperature-thawing time response at $X=3 \mathrm{~m}$ (monitor point 2); (b) variation of required thawing time with ambient temperature inside tunnel. 


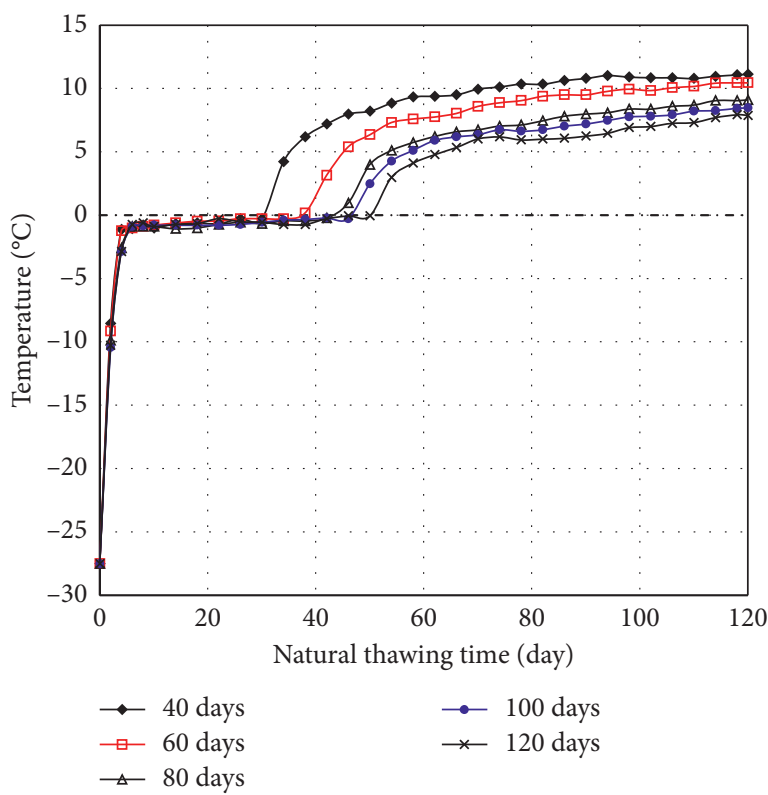

(a)

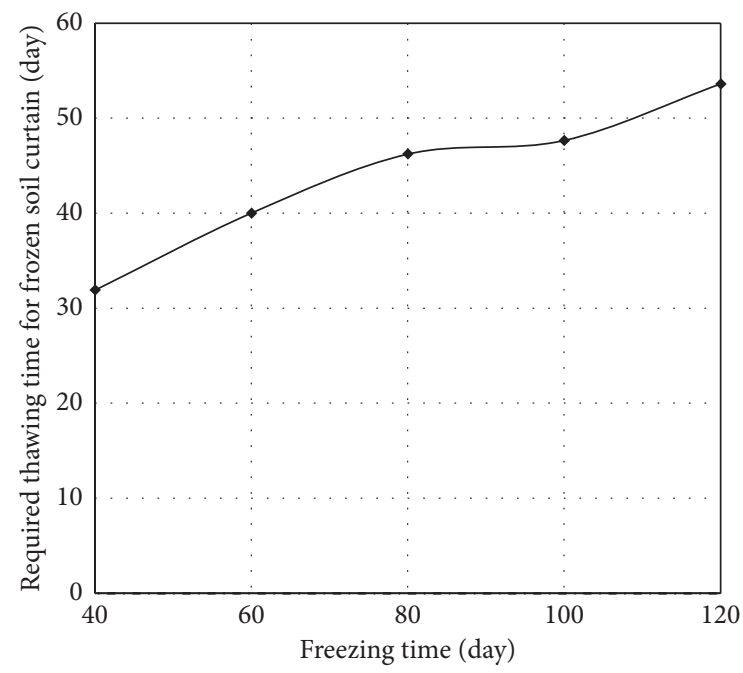

Frozen soil curtain at $x=3 \mathrm{~m}$

(b)

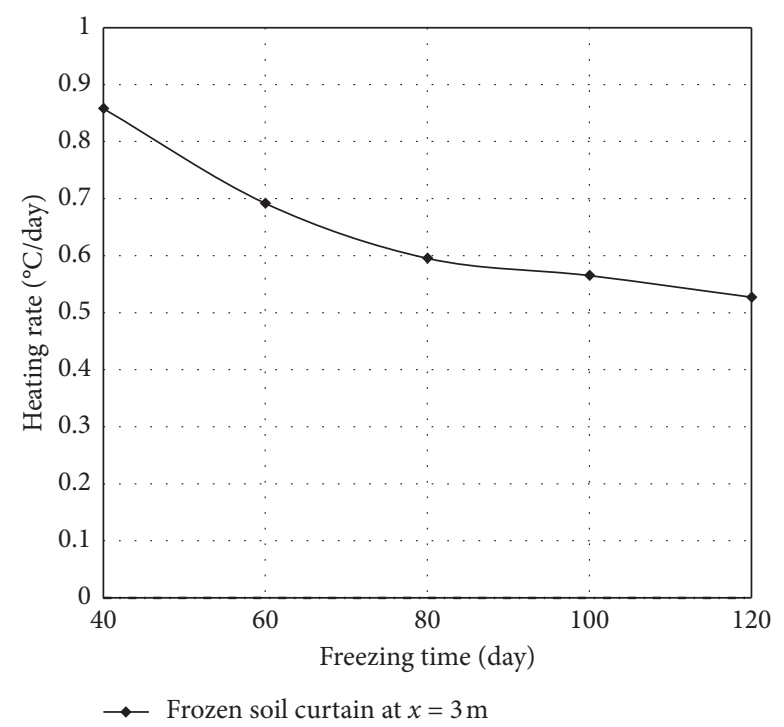

(c)

FiguRE 16: Effects of freezing time on the temperature-thawing time response and required thawing time for frozen soil curtain: (a) temperature-thawing time response at $X=3 \mathrm{~m}$ (monitor point 2); (b) variation of required thawing time with freezing time; (c) variation of heating rate with freezing time.

change time reduces with the increase of thermal conductivity and rises otherwise. This is mainly because the moisture content is the main factor affecting thermal conductivity. Under the same conditions, the increase of thermal conductivity indicates the corresponding increase of moisture content or the enhancement of thermal conductivity performance of soil; as a result, the thawing speed is accelerated, and the time required to reach the phase change is shortened. On the other hand, as shown in Figure 13(b), the required time for the fully thawing of frozen soil curtain decreases approximately linearly with the increase of thermal conductivity. When the thermal conductivity decreases by $40 \%$, the thawing time increases by 20 days, while when the thermal conductivity increases by $40 \%$, the thawing time decreases by 8 days. Therefore, the effect of reducing thermal 


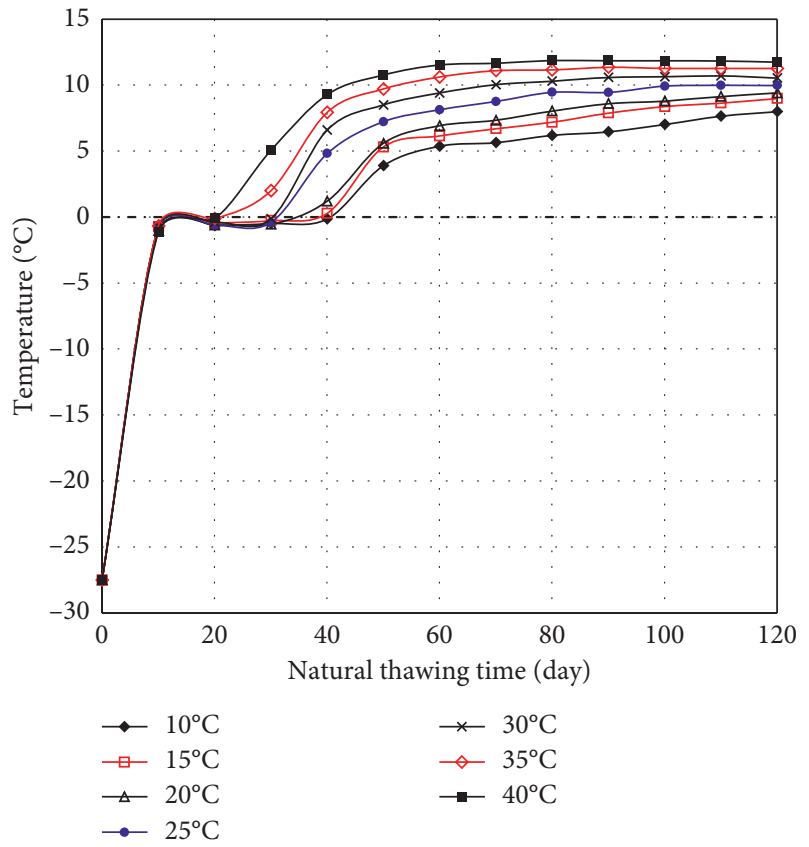

(a)

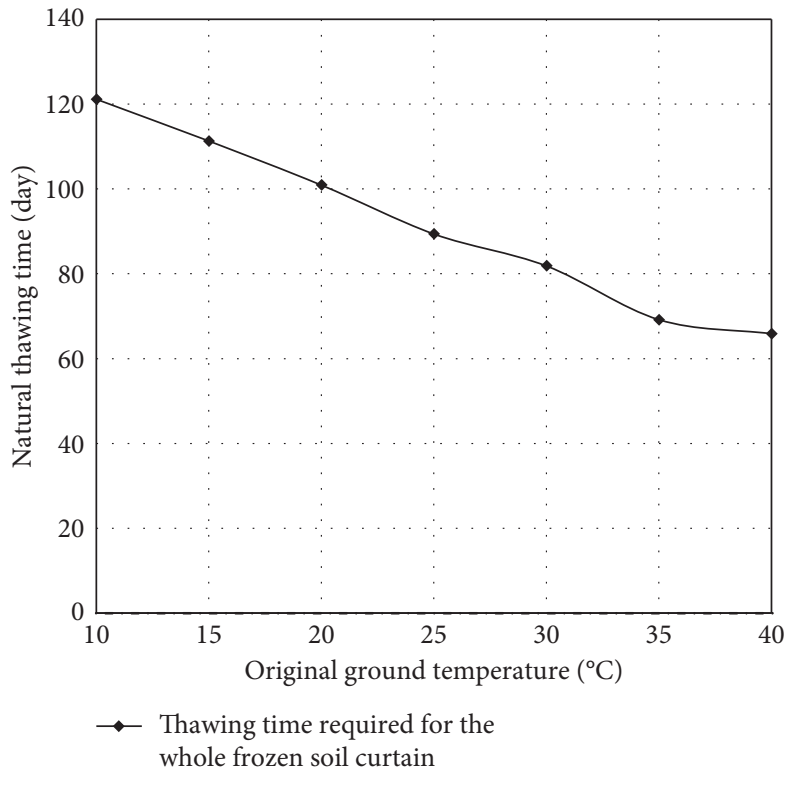

(b)

FIGURE 17: Effects of original ground temperature on the temperature-thawing time response and required thawing time for frozen soil curtain: (a) temperature-thawing time response at $X=3 \mathrm{~m}$ (monitor point 2); (b) variation of required thawing time with original ground temperature.

conductivity on thawing period is greater than that of increasing thermal conductivity.

\subsection{Effect of Latent Heat of Phase Change. Figure 14 provides} the results of temperature-thawing time response at monitor point 2 and required thawing time for frozen curtain for cases with varying latent heat of phase change. Likewise, the latent heat of phase change for the mucky silty clay layer was reduced and increased by $20 \%$ and $40 \%$, respectively, in the finite element computation. As the latent heat of phase change increases, the phase change time is extended accordingly; namely, a $20 \%$ increase in latent heat results in an extension of $\sim 5$ days in the phase change time (Figure 14(a)). On the other hand, in Figure 14(b), the required thawing time for the whole frozen soil curtain also increases approximately linearly with the augment of latent heat of phase change; its increase gradient is around 10 days per $20 \%$ change in latent heat.

5.3. Effect of Ambient Temperature inside Tunnel. The effect of ambient temperature inside tunnel on the thawing temperature of artificial frozen soil is also investigated. Five different ambient temperatures of $5^{\circ} \mathrm{C}, 10^{\circ} \mathrm{C}, 15^{\circ} \mathrm{C}, 20^{\circ} \mathrm{C}$, and $25^{\circ} \mathrm{C}$ were examined. The computed results of temperaturethawing time response at monitor point 2 and required thawing time for the whole frozen curtain are presented in Figure 15. It can be seen in Figure 15(a) that the phase change time decreases with the increase of ambient temperature in the tunnel, notably when the ambient temperature increases from $5^{\circ} \mathrm{C}$ to $10^{\circ} \mathrm{C}$. Similarly, in Figure $15(\mathrm{~b})$, the required thawing time for the whole frozen soil curtain also decreases with the ambient temperature inside tunnel. For instance, the required thawing time is almost halved when the ambient temperature is increased from $5^{\circ} \mathrm{C}$ to $25^{\circ} \mathrm{C}$. It can be found that the decrease of ambient temperature in the tunnel would exert increasing influence on the phase change period in the natural thawing process of horizontal frozen soil curtain. As the phase change period accounts for a large proportion in the whole three-stage thawing process, the decrease of ambient temperature will, therefore, prolong the completion time of natural thawing.

5.4. Effect of Freezing Time. With the extension of freezing time, the average temperature of frozen soil curtain will decrease gradually. In this section, the effect of freezing time on the natural thawing temperature field is analyzed by changing the length of freezing period. Five different freezing periods of 40 days, 60 days, 80 days, 100 days, and 120 days were selected in the analysis. As shown in Figure 16, the phase change time and the required thawing time for frozen soil curtain increase with the extension of freezing time. In contrast, the heating rate declines with the freezing time; namely, when the freezing time increases from 40 days to 80 days, the average heating rate slows down by around $0.3^{\circ} \mathrm{C} /$ day, while when the freezing time increases from 80 
days to 120 days, the reduction in the rate is much lesser which is smaller than $0.1^{\circ} \mathrm{C} /$ day. Moreover, by comparing the freezing time with the thawing time in Figure 16(b), when the freezing time is increased by two times from 40 days to 120 days, the increase in the corresponding thawing time is only 20 days indicating a percentage increase of around $67 \%$. This means a $10 \%$ extension of freezing time will give rise to an increase in the corresponding natural thawing time by only $3.3 \%$ implying a relatively small effect.

5.5. Effect of Original Ground Temperature. For the reinforcement construction project in this study, the original ground temperature is relatively high due to the distribution of hydration heat of cement arising from the deep mixing of cement and soil and the reinforcement of chemical grouting at the end of the tunnel before the implementation of artificial horizontal freezing. According to the measured data, the original ground temperature is around $35^{\circ} \mathrm{C} \sim 40^{\circ} \mathrm{C}$ which is rare in previous municipal freezing projects. There is no doubt that different original ground temperature will exert some influence on the freezing process, but how much it will affect the natural thawing process after the completion of freezing still lacks theoretical and practical investigation. To solve this, seven different original ground temperatures before freezing are considered, that is, $10^{\circ} \mathrm{C}, 15^{\circ} \mathrm{C}, 20^{\circ} \mathrm{C}$, $25^{\circ} \mathrm{C}, 30^{\circ} \mathrm{C}, 35^{\circ} \mathrm{C}$, and $40^{\circ} \mathrm{C}$. These values are determined based on construction experience because the measured original ground temperature in the construction of urban rail transit is normally less than $40^{\circ} \mathrm{C}$. As shown in Figure 17, when the original ground temperature increases from $10^{\circ} \mathrm{C}$ to $40^{\circ} \mathrm{C}$, the corresponding phase change time and the required thawing time for the whole frozen soil curtain decrease gradually. When the temperature is less than $35^{\circ} \mathrm{C}$, the gradient of decease in the required thawing time is around 2 days $/{ }^{\circ} \mathrm{C}$, while when the temperature is more than $35^{\circ} \mathrm{C}$, the required natural thawing time becomes almost the same which is approximately 68 days.

\section{Conclusions}

Based on the horizontal freezing reinforcement project of Chating Station to Jiqingmen Station Tunnel in the Nanjing Metro Line 2, this study systematically investigated the natural thawing heat transfer of artificial frozen soil in shield-driven tunnelling using a three-dimensional finite element method. The spatial variations of temperature field with natural thawing time were explicitly examined. Furthermore, the influencing factors such as the thermal conductivity, latent heat of phase change, ambient temperature inside tunnel, freezing time, and original ground temperature were analyzed in a rational manner. This study may enrich the existing database on the natural thawing temperature behavior of artificial frozen soil surrounding shielddriven tunnels which is currently scarce in both academic and industrial domains. For example, the provided temperature measurements of the thawing process validated the finite element analysis and implied some qualitative agreement. In addition, the reported reinforcement project in this study adopted ununiformed layout of horizontal freezing pipes due to the complex geological conditions; that is, the length of the lower half freezing pipes is twice that of the upper half freezing pipes. This may provide a reference for the assessment of natural thawing heat transfer behavior of frozen soil in projects with similar scenarios.

Based on the sensitivity analysis, some findings are summarized as follows:

(1) The effect of the change in thermal conductivity on the natural thawing process is mainly reflected in the phase change time. The required time for the fully thawing of frozen soil curtain decreases approximately linearly with the increase of thermal conductivity. The effect of reducing thermal conductivity on thawing period is greater than that of increasing thermal conductivity.

(2) As the latent heat of phase change increases, the phase change time is extended accordingly. The required thawing time for the whole frozen soil curtain increases approximately linearly with the augment of latent heat of phase change.

(3) The phase change time decreases with the increase of ambient temperature in the tunnel. The required thawing time for the whole frozen soil curtain decreases with the ambient temperature inside the tunnel.

(4) The phase change time and the required thawing time for frozen soil curtain increase with the extension of freezing time. In contrast, the heating rate declines with the freezing time.

(5) When the original ground temperature increases, the corresponding phase change time and the required thawing time for the whole frozen soil curtain decrease gradually.

It should be noted that this study only considered the typical soil type in Nanjing District and did not account for the influence of geometric dimensions such as the thickness of frozen soil curtain, the length of freezing pipes, and the diameter of tunnel. In addition, the water flow in the ground has not been examined. Therefore, future research might consider the seepage flow in the ground and explore the effects of different soil type and geometric dimension on the natural thawing heat transfer behavior of artificial frozen soil during shield-driven tunnelling.

\section{Data Availability}

The figures/tables data used to support the findings of this study are included within the article.

\section{Conflicts of Interest}

The authors declare that they have no conflicts of interest. 


\section{Acknowledgments}

This research was supported by the Hainan Major Science and Technology Project (ZDKJ201803), the National Natural Science Foundation of China (51968019), the High-Level Talent Project of Hainan Basic and Applied Basic Research Plan (2019RC148 and 2019RC351), the Hainan Natural Science Foundation (518QN307 and 519QN333), and the Sci-Tech Plan Project of Wuhu City (2019yf21).

\section{References}

[1] J. Hu, Y. Liu, H. Wei, K. Yao, and W. Wang, "Finite-element analysis of heat transfer of horizontal ground-freezing method in shield-driven tunneling," International Journal of Geomechanics, vol. 17, no. 10, Article ID 04017080, 2017.

[2] S. Li, F. Niu, Y. Lai, W. Pei, and W. Yu, "Optimal design of thermal insulation layer of a tunnel in permafrost regions based on coupled heat-water simulation," Applied Thermal Engineering, vol. 110, pp. 1264-1273, 2017.

[3] E. Pimentel, S. Papakonstantinou, and G. Anagnostou, "Numerical interpretation of temperature distributions from three ground freezing applications in urban tunnelling," Tunnelling and Underground Space Technology, vol. 28, pp. 57-69, 2012.

[4] G. Russo, A. Corbo, F. Cavuoto, and S. Autuori, "Artificial ground freezing to excavate a tunnel in sandy soil. Measurements and back analysis," Tunnelling and Underground Space Technology, vol. 50, pp. 226-238, 2015.

[5] J. Zhou and Y. Tang, "Practical model of deformation prediction in soft clay after artificial ground freezing under subway low-level cyclic loading," Tunnelling and Underground Space Technology, vol. 76, pp. 30-42, 2018.

[6] P. Eslami-Nejad and M. Bernier, "Freezing of geothermal borehole surroundings: a numerical and experimental assessment with applications," Applied Energy, vol. 98, pp. 333-345, 2012.

[7] M. Vitel, A. Rouabhi, M. Tijani, and F. Guérin, "Modeling heat transfer between a freeze pipe and the surrounding ground during artificial ground freezing activities," Computers and Geotechnics, vol. 63, pp. 99-111, 2015.

[8] M. Vitel, A. Rouabhi, M. Tijani, and F. Guérin, "Modeling heat and mass transfer during ground freezing subjected to high seepage velocities," Computers and Geotechnics, vol. 73, pp. 1-15, 2016.

[9] A. Marwan, M.-M. Zhou, M. Zaki Abdelrehim, and G. Meschke, "Optimization of artificial ground freezing in tunneling in the presence of seepage flow," Computers and Geotechnics, vol. 75, pp. 112-125, 2016.

[10] M. Vitel, A. Rouabhi, M. Tijani, and F. Guérin, "Thermohydraulic modeling of artificial ground freezing: application to an underground mine in fractured sandstone," Computers and Geotechnics, vol. 75, pp. 80-92, 2016.

[11] M. A. Alzoubi, A. Madiseh, F. P. Hassani, and A. P. Sasmito, "Heat transfer analysis in artificial ground freezing under high seepage: validation and heatlines visualization," International Journal of Thermal Sciences, vol. 139, pp. 232-245, 2019.

[12] W. Fan and P. Yang, "Ground temperature characteristics during artificial freezing around a subway cross passage," Transportation Geotechnics, vol. 20, Article ID 100250, 2019.

[13] X. Hu, S. Deng, and H. Ren, "In situ test study on freezing scheme of freeze-sealing pipe roof applied to the Gongbei tunnel in the
Hong Kong-Zhuhai-Macau bridge," Applied Sciences, vol. 7, no. 1, p. 27, 2016.

[14] S. Huang, Y. Guo, Y. Liu, L. Ke, G. Liu, and C. Chen, "Study on the influence of water flow on temperature around freeze pipes and its distribution optimization during artificial ground freezing," Applied Thermal Engineering, vol. 135, pp. 435-445, 2018.

[15] Z. Li, J. Chen, M. Sugimoto, and H. Ge, "Numerical simulation model of artificial ground freezing for tunneling under seepage flow conditions," Tunnelling and Underground Space Technology, vol. 92, Article ID 103035, 2019.

[16] Y. Liu, J. Hu, H. Xiao, and E. J. Chen, "Effects of material and drilling uncertainties on artificial ground freezing of cementadmixed soils," Canadian Geotechnical Journal, vol. 54, no. 12, pp. 1659-1671, 2017.

[17] A. Rouabhi, E. Jahangir, and H. Tounsi, "Modeling heat and mass transfer during ground freezing taking into account the salinity of the saturating fluid," International Journal of Heat and Mass Transfer, vol. 120, pp. 523-533, 2018.

[18] R. A. Sudisman, M. Osada, and T. Yamabe, "Experimental investigation on effects of water flow to freezing sand around vertically buried freezing pipe," Journal of Cold Regions Engineering, vol. 33, Article ID 04019004, 2019.

[19] H. Tounsi, A. Rouabhi, M. Tijani, and F. Guérin, “Thermohydro-mechanical modeling of artificial ground freezing: application in mining engineering," Rock Mechanics and Rock Engineering, vol. 52, no. 10, pp. 3889-3907, 2019.

[20] J. Park, C.-U. Hyun, and H.-D. Park, "Changes in microstructure and physical properties of rocks caused by artificial freeze-thaw action," Bulletin of Engineering Geology and the Environment, vol. 74, no. 2, pp. 555-565, 2015.

[21] Y.-Q. Tang and J.-J. Yan, "Effect of freeze-thaw on hydraulic conductivity and microstructure of soft soil in Shanghai area," Environmental Earth Sciences, vol. 73, no. 11, pp. 7679-7690, 2015.

[22] J. Zhou and Y. Tang, "Centrifuge experimental study of thaw settlement characteristics of mucky clay after artificial ground freezing," Engineering Geology, vol. 190, pp. 98-108, 2015.

[23] Z. Ding, B. Kong, X. Wei, M. Zhang, B. Xu, and F. Zhao, "Laboratory testing to research the micro-structure and dynamic characteristics of frozen-thawed marine soft soil," Journal of Marine Science and Engineering, vol. 7, no. 4, p. 85, 2019.

[24] W. Fan, P. Yang, and Z. Yang, "Impact of freeze-thaw on the physical properties and compressibility of saturated clay," Cold Regions Science and Technology, vol. 168, Article ID 102873, 2019.

[25] Y. Huang and C. Swan, "Evaluating the behavior of a cohesive soil undergoing one cycle of freeze-thaw," Geotechnical Frontiers, vol. 2017, pp. 643-651, 2017.

[26] H. Lei, Y. Song, Z. Qi, J. Liu, and X. Liu, "Accumulative plastic strain behaviors and microscopic structural characters of artificially freeze-thaw soft clay under dynamic cyclic loading," Cold Regions Science and Technology, vol. 168, Article ID 102895, 2019.

[27] M. E. Orakoglu, J. Liu, and F. Niu, "Experimental and modeling investigation of the thermal conductivity of fiberreinforced soil subjected to freeze-thaw cycles," Applied Thermal Engineering, vol. 108, pp. 824-832, 2016.

[28] Y. Tang and J. Li, "Experimental study on dynamic cumulative axial-strain performance of freezing-thawing saturated sandy silt," Cold Regions Science and Technology, vol. 155, pp. 100-107, 2018. 
[29] J. Zhou and Y. Tang, "Artificial ground freezing of fully saturated mucky clay: thawing problem by centrifuge modeling," Cold Regions Science and Technology, vol. 117, pp. 1-11, 2015.

[30] Y. Zhao, B. Yu, G. Yu, and W. Li, "Study on the water-heat coupled phenomena in thawing frozen soil around a buried oil pipeline," Applied Thermal Engineering, vol. 73, no. 2, pp. 1477-1488, 2014.

[31] P.-P. He and Z.-D. Cui, "Dynamic response of a thawing soil around the tunnel under the vibration load of subway," Environmental Earth Sciences, vol. 73, no. 5, pp. 2473-2482, 2015.

[32] J. Li, Y. Tang, P. Yang, and Q. Liu, "Dynamic properties of freezing-thawing muddy clay surrounding subway tunnel in Shanghai," Environmental Earth Sciences, vol. 74, no. 6, pp. 5341-5349, 2015.

[33] W. M. Rohsenow, J. P. Hartnett, and E. N. Ganic, Handbook of Heat Transfer Fundamentals, McGraw-Hill Book Co., New York, NY, USA, 1992.

[34] M. A. Alzoubi, A. Nie-Rouquette, and A. P. Sasmito, "Conjugate heat transfer in artificial ground freezing using enthalpy-porosity method: experiments and model validation," International Journal of Heat and Mass Transfer, vol. 126, pp. 740-752, 2018.

[35] K.-Q. Li, D.-Q. Li, and Y. Liu, "Meso-scale investigations on the effective thermal conductivity of multi-phase materials using the finite element method," International Journal of Heat and Mass Transfer, vol. 151, Article ID 119383, 2020.

[36] J. Liu, X. Liang, Y. Xue, K. Yao, and Y. Fu, "Numerical evaluation on multiphase flow and heat transfer during thermal stimulation enhanced shale gas recovery," Applied Thermal Engineering, vol. 178, Article ID 115554, 2020.

[37] D.-W. Li, J.-H. Fan, and R.-H. Wang, "Research on viscoelastic-plastic creep model of artificially frozen soil under high confining pressures," Cold Regions Science and Technology, vol. 65, no. 2, pp. 219-225, 2011.

[38] H. Song, Z. S. Xie, H. Y. Zheng, and W. Zhang, "Numerical simulation for temperature field of subgrade on seasonal frozen area," in Proceedings of the International Conference on Transportation Engineering 2007, pp. 1753-1758, Shanghai, China, July 2007.

[39] O. B. Andersland and B. Ladanyi, An Introduction to Frozen Ground Engineering, Springer Science \& Business Media, Berlin, Germany, 2013. 